Robles Moreno, J. (2020): “Fortificaciones iberorromanas: el caso de la puerta oriental de Torreparedones (Baena, Córdoba)", Spal 29.2: 81-107. DOI: https://dx.doi.org/10.12795/spal.2020.i29.19

\title{
FORTIFICACIONES IBERORROMANAS: EL CASO DE LA PUERTA ORIENTAL DE TORREPAREDONES (BAENA, CÓRDOBA)
}

\section{IBERO-ROMAN FORTIFICATIONS: TORREPAREDONES (BAENA, CÓRDOBA) EASTERN GATE}

\author{
JESÚS ROBLES MORENO \\ Contratado Predoctoral FPU (MICINN), Departamento de Prehistoria y Arqueología, \\ Universidad Autónoma de Madrid. Facultad de Filosofía y Letras, C/Francisco Tomás y Valiente, 1 \\ Campus de Cantoblanco, Universidad Autónoma de Madrid, 28049 Madrid. \\ Correo-e: jesus.robles@uam.es (D) https://orcid.org/0000-0002-5276-1974 \\ ResearcherID: <https://publons.com/researcher/AAG-8294-2019>
}

\begin{abstract}
Resumen: En el presente artículo se abordan las estructuras que integran el conjunto de acceso oriental del yacimiento ibero-romano de Torreparedones (Baena, Córdoba), una puerta urbana fortificada construida hacia la segunda mitad del siglo I a.C. El estudio arquitectónico de los restos conservados y su interpretación, partiendo de una serie de paralelos peninsulares y mediterráneos, permite comprender el funcionamiento de la puerta y su sistema de control de paso. Se identifica así un acceso de tipo "patio" en el que las torres y, probablemente, las máquinas de artillería jugaron un importante papel en la defensa de la ciudad.
\end{abstract}

Palabras clave: II Edad del Hierro, Romanización, puertas urbanas, arquitectura defensiva iberorromana, artillería

\begin{abstract}
This paper analyses the eastern gate structures of the Ibero-Roman site of Torreparedones (Baena, Córdoba), a fortified urban gate built around the second half of the first century b.C. The architectural study of the remains and their interpretation - considering Mediterranean and Peninsular parallels - allows us to understand how this gate system worked. Thus, it can identified as a "courtyard gate", where towers and, possibly, artillery played an important role in the city's defence.
\end{abstract}

Keywords: Second Iron Age, Romanization, urban gates, Ibero-roman defensive architecture, artillery

\section{INTRODUCCIÓN: EXCAVACIONES EN LA PUERTA ORIENTAL DE TORREPAREDONES}

Torreparedones es un yacimiento ubicado en la campiña oriental cordobesa, en los límites del término municipal de Baena (Córdoba), muy cerca por tanto de la provincia de Jaén. Físicamente se encuentra en una planicie situada a $580 \mathrm{~m}$ sobre el nivel del mar, lo que supone una de las cotas más elevadas del valle del Salsvm (Guadajoz) (fig. 1), río localizado a $10 \mathrm{~km}$ del asentamiento. Cuenta con un perímetro amurallado que cubre 10.5 ha de extensión, en los que las sucesivas campañas de excavación han permitido atestiguar una 
ocupación que se extiende desde el Neolítico hasta el siglo XVII d.C., momento en el que se abandona la Ermita de las Vírgenes (Morena 2019). Entre los numerosos restos conservados resultan de especial interés los de época romana, como el santuario periurbano (Morena 2018), el foro (Ventura 2014) o el recientemente hallado anfiteatro (Monterroso-Checa et al. 2019).

Aunque este yacimiento es conocido desde antiguo, debido a hallazgos casuales como fue el "Mausoleo de los Pompeyos" (Maier 2010), las primeras excavaciones científicas en el mismo tuvieron lugar entre 1987 y 1992, bajo la dirección de Barry Cunliffe y M. Cruz Fernández. Estas se desarrollaron en el marco de The Guadajoz Proyect, un proyecto coordinado por la Universidad Complutense de Madrid, la Universidad de Córdoba y el Instituto de Arqueología de la Universidad de Oxford que nació con el objetivo de realizar un primer acercamiento al yacimiento, su entorno y su secuencia ocupacional. Para ello se llevaron a cabo una serie de sondeos que permitieron identificar la muralla, algunos espacios intramuros, el santuario y la puerta oriental (Cunliffe y Fernández 1999).

Esta última se descubrió concretamente en la campaña de 1990 mediante un sondeo de limpieza superficial, con el que se corroboró la existencia de un vano entre dos torres. Un segundo sondeo, ya de excavación, permitió documentar al completo la torre sur y su relación con la muralla (Cunliffe y Fernández 1992, Cunliffe y Fernández 1999: 33). Fruto de estas primeras excavaciones y del estudio de materiales los autores establecieron la cronología de este conjunto en los siglos IV-III a.C. (Cunliffe y Fernández 1999: 72) (vid. infr.).

El conjunto permaneció en este estado de la cuestión hasta el año 2006, cuando bajo la dirección de J.A. Morena se retomaron los trabajos en el yacimiento, con intervenciones arqueológicas en el santuario y la puerta oriental. En este último sector se plantearon seis cortes (Corte 5A-Corte 55) que abarcaron una superficie de $515 \mathrm{~m}^{2}$, lo que permitió conocer la práctica totalidad de las estructuras que integran este conjunto de acceso. Además, en esta campaña se documentaron nuevos materiales que, sumados a la revisión de los exhumados en 1990, permitieron modificar la cronología propuesta y datar la construcción de esta puerta en la segunda mitad del siglo I a.C. (Morena 2010: 178, Morena y Moreno 2010: 441, Moreno 2014: 40). Los resultados de esta última campaña han sido publicados de manera preliminar (Morena 2010, Morena y Moreno 2010, Moreno 2014) presentando así los restos exhumados e incidiendo someramente en algunos aspectos como la nueva propuesta cronológica del conjunto o las técnicas constructivas en él empleadas. Sin embargo, una construcción de esta envergadura y con las particularidades que reúne merece estudios más detallados, que permitan profundizar en cuestiones apenas abordadas hasta la fecha. Una de ellas, objetivo principal de nuestro trabajo, es la interpretación conjunta de los restos conservados para comprender el funcionamiento de esta puerta y su sistema de control del paso. Partiendo así de los datos arquitectónicos, y empleando los pertinentes paralelos, se podrá entender mejor la puerta y el sistema defensivo en su contexto histórico.

\section{ESTRUCTURAS QUE INTEGRAN LA PUERTA ORIENTAL}

Las dos campañas de excavación, en 1990 y 2006, que han tenido como objeto la puerta oriental de Torreparedones han permitido sacar a la luz un masivo conjunto de acceso fortificado, hasta ahora el único excavado y documentado del yacimiento (fig. 2). Para referirnos a las unidades que se pueden consultar en el plano, emplearemos las denominaciones dadas por sus excavadores. En el caso de las de 1990 será F y el número de unidad, y en el de las 2006 se empleará el número del sector (5), la letra del corte (A-F) y el número de U.E. o U.C.

Este conjunto se localiza en el sector oriental del trazado murario, entre las llamadas "torres 6 y 7 " por Cunliffe y Fernández (1999: 54) y en su entorno se han podido documentar los restos de un camino de acceso pavimentado con caliza y cantos rodados en el tramo más cercano (UC 5A 26) al conjunto. Algo más alejada, a unos $200 \mathrm{~m}$ de esta puerta, se encuentra la necrópolis oriental del yacimiento, cuyas tumbas más antiguas, entre las que destaca la de un soldado romano, se remontan al cambio de era (Tristell y López 2014).

\subsection{Las torres}

De las diversas estructuras que integran el conjunto de acceso oriental de Torreparedones, las más destacables son quizá las dos torres que flanquean el acceso a la ciudad, disposición frecuente en el mundo ibérico (Moret 1996: 121). Estas presentan una planta rectangular con dimensiones prácticamente análogas: la torre sur mide $10.15 \mathrm{~m}$ y $10.30 \mathrm{~m}$ en sus lados largos y $8.20 \mathrm{~m}$ en los lados cortos, mientras que la norte presenta lados largos de $9.72 \mathrm{~m}$ y lados cortos de $7.98 \mathrm{~m}$. Estas medidas, cercanas a un cuadrado de proporción 1:1.2 


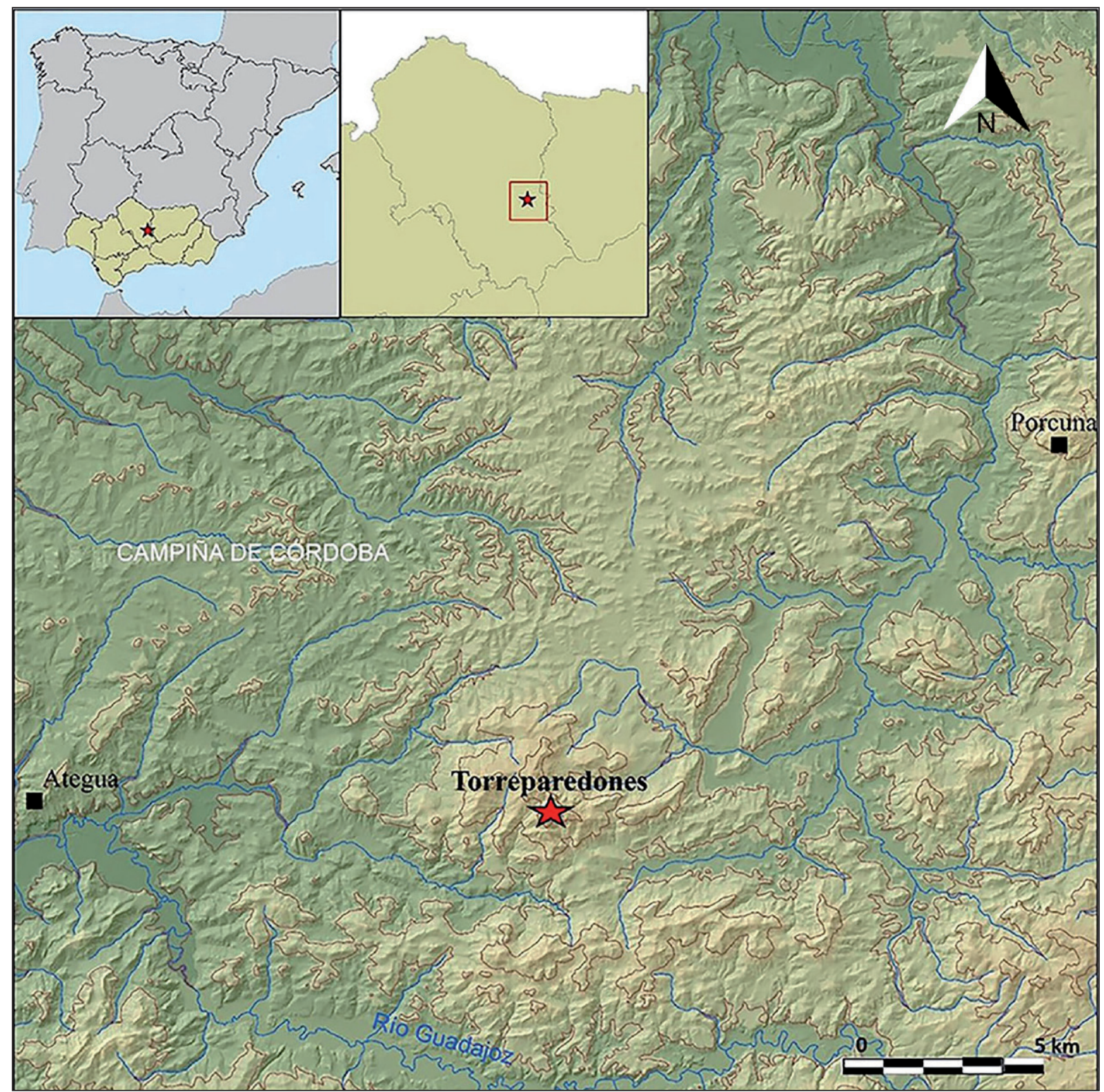

Figura 1. Ubicación del yacimiento de Torreparedones (Baena, Córdoba) (Base Cartográfica del IGN con edición de M. Camacho).

(Morena 2010: 176), se pueden descomponer en codos de $0.514 \mathrm{~m}$ (Moret 1998: 20, Moret 2002), una unidad métrica de base púnica que pervive en zonas de fuerte influencia cartaginesa (Barresi 1991 y 2007: 25). Por tanto, no es de extrañar su empleo en este yacimiento, donde existe gran pervivencia púnica, incluso en época romana imperial. Prueba de ello es el santuario iberorromano, cuya arquitectura y culto es de raigambre púnica (Morena 2018: 77 y ss.), así como los enterramientos imperiales en cámaras subterráneas que ilustran también esa influencia (Tristell y López 2014: 112). Esta unidad métrica, documentada en las mensae ponderariae del mercado de Thibillis (Argelia) (Ioppolo 1967), es la empleada en la Torre II de Lucentum (Tossal de Manises, Alicante), datada a finales del siglo II a.C. o comienzos del I a.C. (Olmos Benlloch 2010: 299-300).

De estas torres sólo conservamos los zócalos de piedra, con muros de $2 \mathrm{~m}$ de grosor, conseguidos mediante la técnica del emplecton. El aparejo del paramento

ISSN: 1133-4525 ISSN-e: 2255-3924 


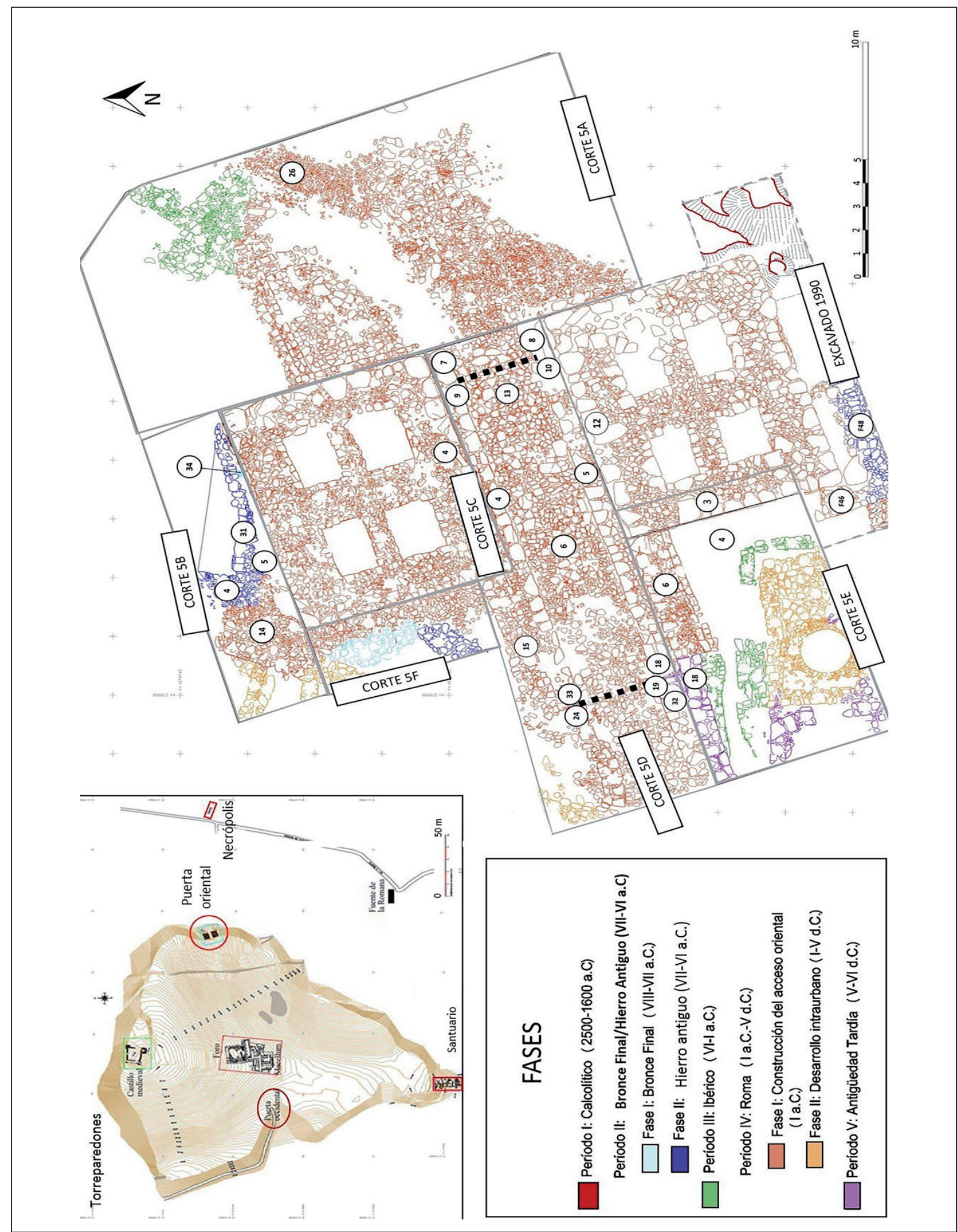

Figura 2. Planimetría del conjunto de acceso con indicación de las unidades mencionadas en el texto Las líneas negras punteadas marcan la ubicación de las dos puertas (Adaptado de Robles et al. (e.p.). 


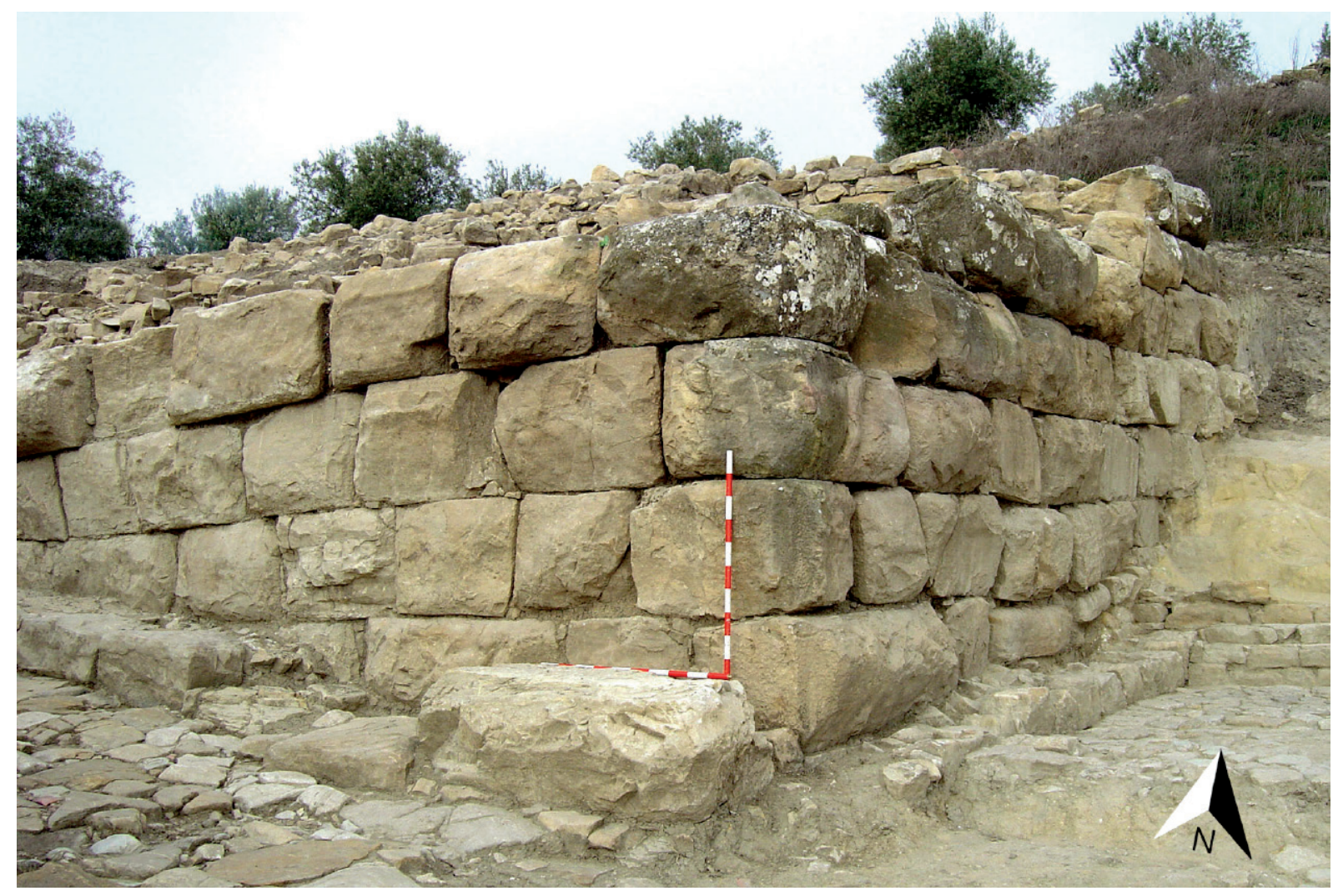

Figura 3. Detalle del zócalo de la torre norte. Obsérvese el aparejo (Imagen cedida por J.A. Morena).

externo está formado por grandes bloques de caliza local, cuyas aristas exteriores se han rebajado con respecto al centro, generando un listel perimetral que da lugar a un almohadillado rústico (Morena 2010: 177) (fig. 3). Estos sillares se disponen a hueso, formando hiladas cuya regularidad se consigue mediante el empleo de engatillados, ripios y cuñas. Todas estas características permiten catalogar el aparejo de estas torres como un opus siliceum de la IV maniera de Lugli (1957: 80). Se trata de una técnica constructiva con cercanos paralelos peninsulares (Asensio Esteban 2006: 120 y ss.) como son las dos puertas augusteas de Baelo Claudia. Del mismo modo, este aparejo está presente en varios de los llamados "recintos fortificados" que se sitúan en el entorno inmediato de Torreparedones, como es el caso de El Higuerón (Moret 1996: 585), Las Almayas o Las Piedras de Gilica (Morena et al. 1990, Cunliffe y Fernández 1992: 237).

Los zócalos de las torres son macizos e inaccesibles, pues no cuentan con accesos a nivel de suelo y su interior aparece relleno de tierra y cascote (fig. 4). Llama la atención el sistema constructivo aquí presente, ya que encontramos en el interior dos muros transversales que conforman una cruz, también denominados muros de riostra (Montanero 2008: 96), y generan así cuatro compartimentos. Estos no son espacios útiles, ya que no son la finalidad de colocar esos muros de riostra, sino una consecuencia de los mismos (Berrocal-Rangel y Moret 2007: 26). Estos muros funcionan como tirantes que evitan que el empuje generado por el relleno del zócalo provoque el colapso de las estructuras.

En ese sentido, se trata de un principio constructivo básico: el mismo que aparece en las murallas de cajones de raigambre fenicio-púnica (Escacena 2002; Montanero 2008: 96 con bibliografía, Marín Martínez 2012: 10), como es la propia muralla de Torreparedones (Cunliffe y Fernández 1999: 40), si bien esta es anterior a la construcción de la puerta romana (vid. infr.). Esta disposición matricial de los paramentos transversales en el interior de las torres halla paralelos en varios casos mediterráneos que se concentran en los siglos IV-III a.C. como son varias de las que jalonan la muralla de Halicarnaso (Pedersen 2010: 281). Karlsson (1992) recoge esta solución en diecisiete casos de diferentes yacimientos sicilianos, como es la torre B de Siracusa o las torres IV y V de Megara Hyblaea. Otro

ISSN: 1133-4525 ISSN-e: 2255-3924 
ejemplo más cercano en el tiempo y el espacio es el zócalo de la torre del faro de Onuba Aestuaria (Huelva), datado entre el siglo I a.C. y el I d.C. (Campos y Bermejo 2017: 759).

Los casos sicilianos permitieron a Moret (1996: 210-211), basándose en la cronología del Ibérico Pleno propuesta por Cunliffe y Fernández (1999: 72), señalar que este modelo pudo ser importado por mercenarios íberos o generales cartagineses que lucharon en Sicilia. La nueva datación de la puerta obliga a matizar esta interpretación, descartando esa importación directa por parte de dichos militares. Sin embargo, hay que considerar la importancia que los púnicos tienen en el desarrollo de la arquitectura de la península ibérica, no solo importando formas arquitectónicas y defensivas propias, sino como difusores de los modelos helenísticos y mediterráneos en nuestra península (Montanero 2008: 103 y ss., Marín Martínez 2012, Del Reguero 2019: 234). Esto es algo especialmente relevante en nuestro caso, ya que como hemos mencionado, en este yacimiento son numerosos los aspectos de raigambre púnica que perviven incluso en época romana imperial. En el caso concreto de las torres, podemos apreciar esos aspectos en la unidad metrológica y quizá en los muros de riostra que originan esos compartimentos macizos.

Según algunos autores, la presencia de esta solución constructiva en las torres puede responder a la presencia de artillería en las cámaras superiores, ya que permitiría aguantar mejor el peso de las máquinas (Winter 1971: 182-183, Pedersen y Ruppe 2016: 75). Bakhuizen (1992: 142) en cambio señala que la relación con la artillería no se debe a un mejor aguante de peso, sino a que ese sistema permite dar mayor altura a las torres y por tanto, mejora el ángulo de tiro de esas máquinas. En la misma línea, Morena y Moreno (2010: 441) proponen que el centro de esa cruz serviría como punto de apoyo para un pie derecho que sustentaría una segunda cámara, como ocurre en la Torre de Minerva de Tarraco (Hauschild 1985 y 2006, Ruiz de Arbulo 2007: 567594), si bien en este caso no existen esas cruces internas y está ligeramente desplazado con respecto al centro.

Sobre el desarrollo en altura de las torres poco se puede saber, pues el máximo conservado de los zócalos es de $2.9 \mathrm{~m}$. No obstante, como en esa dimensión no quedan huellas de las estructuras necesarias para enmarcar la parte superior de la puerta, es de suponer que los zócalos serían de mayor altura, pudiendo alcanzar en torno a $5 \mathrm{~m}$ o más, como es el caso del zócalo de $6.20 \mathrm{~m}$ de altura que presenta la Torre de Minerva en Tarraco (Hauschild 1977). A dicha altura le tendríamos que sumar el alzado, con lo que la torre podría alcanzar $10 \mathrm{~m}$ e incluso más gracias a ese sistema de cruces internas, ya que la altura es un factor imprescindible para que las posibles máquinas obtengan mejor ángulo de tiro.

Se desconocen también las características del alzado, pues podría ser macizo en su totalidad, como señalaron Cunliffe y Fernández (1990: 237, 1999: 62) o, más probablemente por el contexto de construcción (vid. infr.), podría contar con una o varias cámaras en altura (Moreno 2014: 429). Ese cuerpo superior podría ser totalmente de piedra, aunque quizá de material y aparejo más liviano que el del zócalo, o bien ser de adobe o tapial, algo frecuente en el mundo antiguo ya que requiere menor tiempo de construcción y reparación (Maher 2012: 61). Además, como señala Pausanias (8.8.8), la arquitectura del barro absorbe mejor las vibraciones provocadas por el impacto de proyectiles, impidiendo que el resto del muro se resienta (Adam 1982: 182, Pope 2016: 264).

En este caso concreto no podemos decantarnos por una u otra opción, debido a la falta de evidencias: el nivel de derrumbe estaba alterado por los niveles de ocupación tardoantigua y las labores agrícolas a lo largo de los siglos. Quizá los sillares escuadrados de tamaño pequeño y mediano, agrupados en un enorme majano entre ambas torres, pudieron formar parte de ese alzado, aunque esto es una mera suposición pues las piedras pueden proceder de otros puntos del yacimiento, habiéndose amontonado ahí tras siglos de labranza.

\subsection{El sistema de acceso}

Entre ambas torres, sin la presencia de cortinas, se encuentra el único vano de acceso de este conjunto oriental. Tiene una anchura total de $4.53 \mathrm{~m}$, aunque la presencia de las dos jambas de la puerta exterior deja una superficie de paso de $2.64 \mathrm{~m}$. Este vano da acceso al decumanus maximus (Moreno 2014: 43) del que se han excavado aquí los primeros metros. Se trata de un viario pavimentado con losas irregulares de caliza (UC 5D 6) que presenta una pendiente total del 13.9\% hacia el interior de la ciudad. Consta de un espacio central por el que discurrían carros, como indican las rodadas conservadas sobre el mismo (Moreno 2014: 44), y dos aceras laterales para el tránsito de los peatones (UC 5D 4; UC 5D 5) que presentan $70 \mathrm{~cm}$ de anchura media y una altura máxima de $35 \mathrm{~cm}$, que disminuye siguiendo la pendiente hacia el interior (fig. 5).

Sobre este tramo de viario excavado se encontraban dos puertas que se han podido atestiguar únicamente 


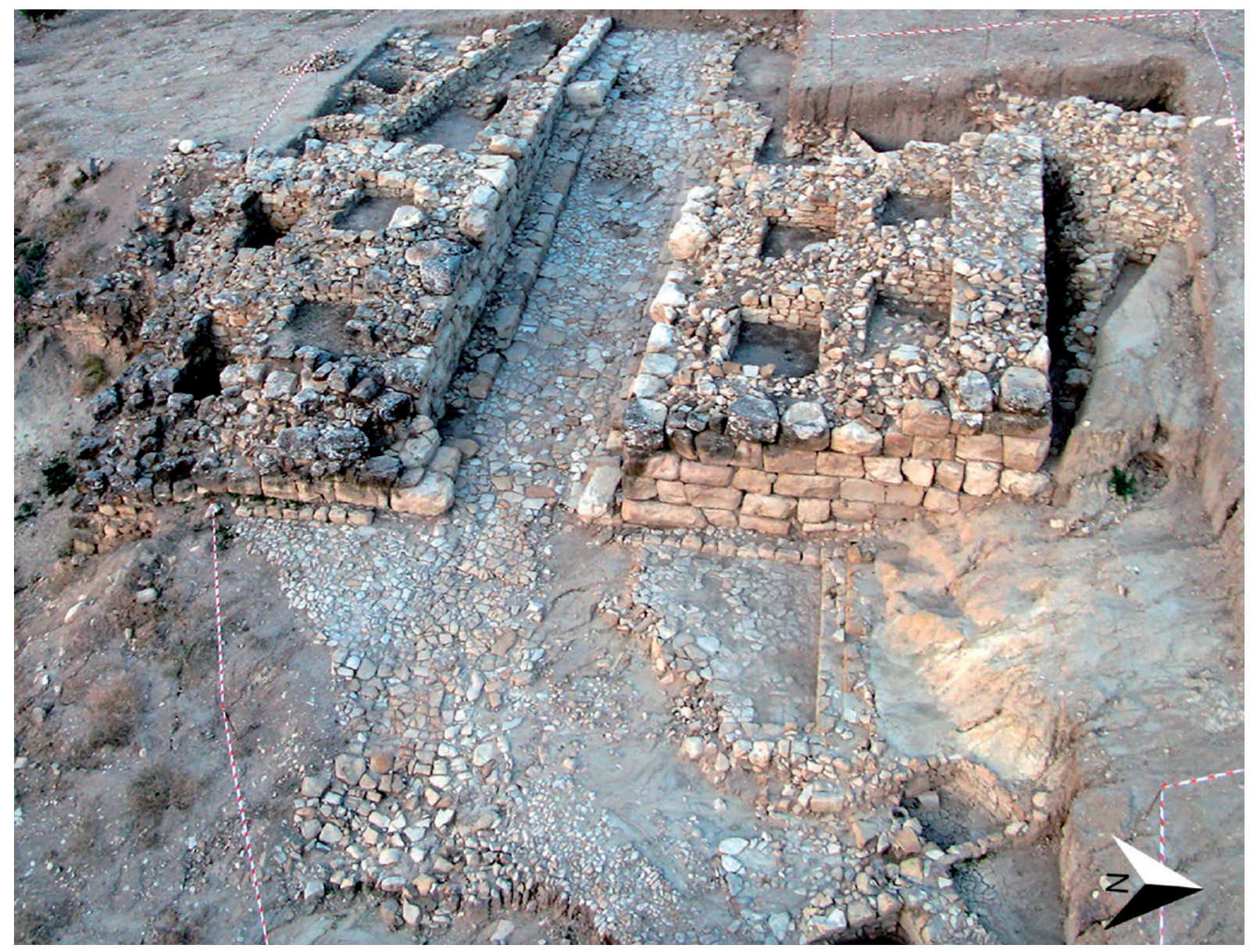

Figura 4. Imagen aérea de las estructuras que conforman el conjunto de acceso al término de la campaña de 2006. Obsérvense las cruces internas en el interior de las torres (Imagen cedida por J.A. Morena).

gracias a los elementos de encaje y sujeción de las mismas, pues no se han conservado elementos metálicos que permitan siquiera una reconstrucción parcial de sus hojas, como ocurre en otros casos (Tortajada 2011: 18). La primera de estas puertas se documenta prácticamente entre las esquinas exteriores de ambas torres: es una puerta de doble batiente, como indican sus quicialeras (UC 5D 9; UC 5D 10), que abriría únicamente hacia el interior, dada la posición de las jambas (UC 5D 7; UC 5D 8) (fig. 6). Vinculado a esta primera puerta aparece un hueco rectangular excavado en el viario (UC 5D 13), situado aproximadamente $1 \mathrm{~m}$ por detrás de la línea marcada por las hojas de la puerta cuando estas estaban cerradas. La función de este hueco sería la de alojar una tranca que, colocada en posición oblicua, permitiese reforzar el cierre de la puerta (Moreno 2014: 43).

La segunda puerta se localiza a $14.30 \mathrm{~m}$ en línea recta hacia el interior de la ciudad y es también identificable por sus quicialeras (UC 5D 19; UC 5D 24), si bien la izquierda está amortizada por un muro tardoantiguo (UC 5D 32), y sus jambas (UC 5D 18; UC 5D 33) (fig. 6). La presencia de estos elementos permite saber que se trataría también de una puerta de doble batiente con apertura hacia el interior. Hacia el centro de este segundo vano, en el espacio en el que coincidían ambas hojas se ha documentado una piedra de pudinga que funcionaría como tope de las mismas (UC 5D 23) (Morena 2010: 178).

En el registro arqueológico no se han reportado evidencias de las estructuras en las que debían encajar las hojas de la puerta por su parte superior, como pudieran ser arcos o dinteles, ni han quedado huellas de las mismas en el zócalo. Únicamente podemos saber que estas superestructuras tuvieron una anchura de $1.7 \mathrm{~m}$ en la primera puerta y en torno a $1 \mathrm{~m}$ en la segunda, ya que es el ancho resultante de sumar las jambas y

ISSN: 1133-4525 ISSN-e: 2255-3924 


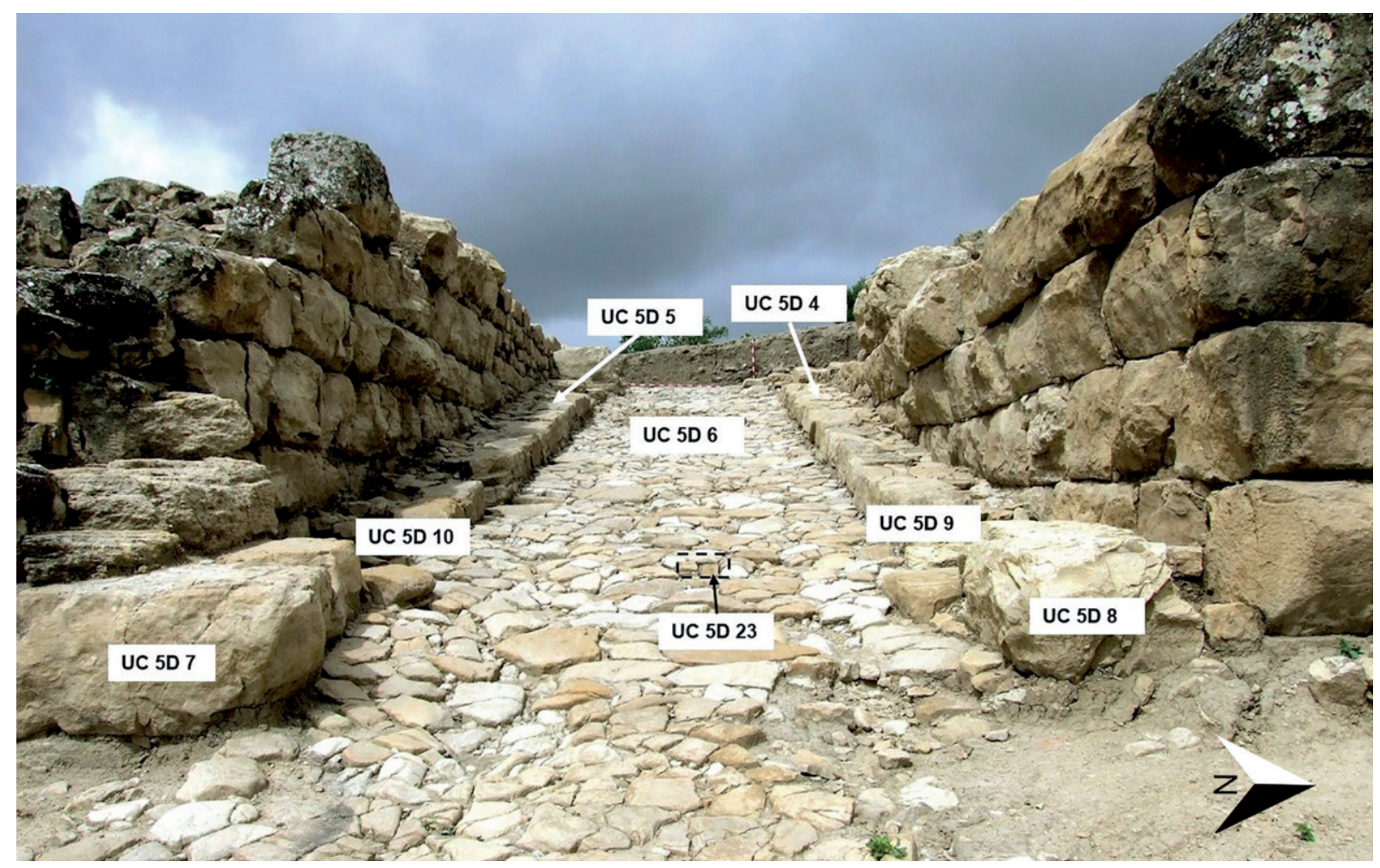

Figura 5. Vista frontal del vano de acceso a la ciudad, con indicación de las diferentes unidades mencionadas en el texto (Imagen cedida por J.A. Morena).

quicialeras sobre las que se sustentarían. Estos arcos o dinteles aparecerían únicamente sobre las puertas, pues dada la configuración de las torres y el sistema defensivo aquí existente (vid. infr.), en ningún caso existiría cubrición sobre la totalidad del espacio entre ambas puertas, como pudiera ser una bóveda.

Este espacio de viario entre ambas puertas se encuentra delimitado en sus laterales, primero por las fachadas de las torres (UC 5C 4; UC 5D 12) y después por dos muros en sentido este-oeste, que nacen de la parte posterior de las mismas y se prolongan hasta la segunda puerta (U.C. 5E 6; U.C. 5D 15) (fig. 7). De hecho, aunque pueda parecer que el muro sur (UC 5E 6) continúa más allá de la segunda puerta, esto no es así, sino que ese es una amortización tardoantigua del espacio de viario (UC 5E 18), probablemente de un muro de vivienda (Morena 2010: 179) (fig. 2 y fig. 7). Mientras que el muro sur se conserva bien, el norte está algo más arrasado por los deslizamientos procedentes de la ladera. En cualquier caso, ambos presentan las mismas características: son muros de $1.5 \mathrm{~m}$ de grosor, construidos con la técnica del emplecton. Sus paramentos están conformados por sillares de mediano tamaño, en torno a $50 \mathrm{~cm}$ de longitud, ligeramente careados y trabados con tierra en hiladas pseudoisódomas. Estos muros no son la fachada de ninguna edificación, sino que son una parte del programa constructivo de esta puerta y como tal, juegan un importante papel en el sistema defensivo de la misma.

\section{DATACIÓN DEL CONJUNTO DE ACCESO}

Todas las estructuras descritas en el apartado anterior forman parte de un mismo programa constructivo en cuya cronología profundizaremos a continuación. Para ello, es necesario prestar atención al registro arqueológico, pues los niveles de ocupación que aquí se han podido documentar se extienden desde el Calcolítico hasta la Antigüedad Tardía, distinguiéndose así un total de cinco períodos (Morena 2010) (fig. 2). Por ceñirnos al tema, la interpretación de las estructuras de la puerta romana y su funcionamiento, no es posible desarrollar aquí la secuencia cronológica de este sector al completo, objetivo de próximos trabajos (Robles et al. e.p.). Bastará con señalar que se han podido conocer las 

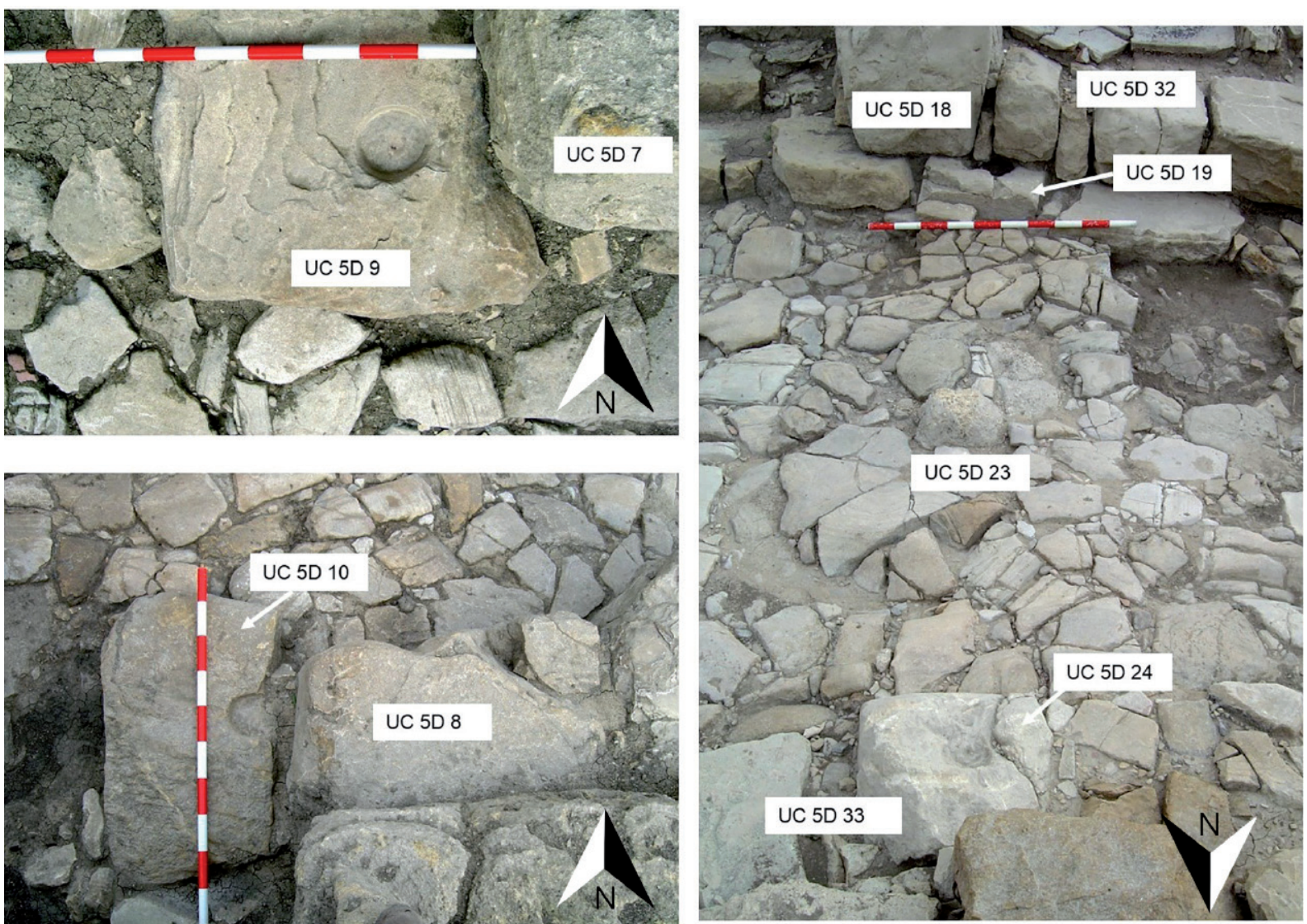

(izquierda) y de la segunda (derecha). (Imagen cedida por

Figura 6. Imagen de las jambas y quicialeras de la primera puerta (izqu
J.A. Morena)

sucesivas modificaciones que se producen en el entorno de este acceso, documentándose así una primera muralla del Bronce Final (UC 5B 34) ya identificada por Cunliffe y Fernández (1999: 56), así como algunos tramos de la muralla posterior (UC 5B 4/ F48).

Esta segunda muralla, cuyo trazado rodea el yacimiento, fue datada por Cunliffe y Fernández (1999: 71) en el siglo VI a.C., si bien esa datación es susceptible de ser revisada mediante futuras excavaciones que complementen los sondeos ya realizados. En cualquier caso, se trata de una obra de gran envergadura, con un trazado de $1.5 \mathrm{~km}$ en los que mantiene una anchura media de 6-7 m. Este trazado se encuentra además jalonado por una serie de torres o bastiones (Cunliffe y Fernández 1999: 31-34). Se conserva de ella el zócalo de piedra macizo, ya que, como hemos adelantado, se trata de una muralla de compartimentos, cuyos paramentos externos están formados por bloques de caliza de gran tamaño, ligeramente desbastados (Cunliffe y Fernández 1999: 40, Moreno 2014: 40). La altura máxima conservada es de $2.8 \mathrm{~m}$ de altura que se completaría con un posible alzado de adobe.

Perteneciente a este mismo circuito murario, y con anterioridad a la puerta romana, existió en este sector un conjunto de acceso que constaba de una sola torre o bastión situado en el flanco izquierdo. Los escasos restos de la misma, apenas el arranque de un paramento (UC 5B 31), se han conservado soterrados en la zanja de cimentación de la torre norte romana (UC 5B 5) (fig. 8). Esto se debe a la envergadura de la obra que requiere el conjunto de acceso romano, en especial a la excavación de las zanjas de cimentación de las torres, que provocan el arrasamiento de las estructuras precedentes como son este bastión y los tramos de muralla más próximos a este sector.

No obstante, si bien se construye un nuevo conjunto de acceso, que no aprovecha estructura alguna del anterior, no se va a levantar una nueva muralla para el asentamiento, sino que se reconstruyen aquellos tramos que habían sido afectados (UC 5B 14/ F46). De esta 


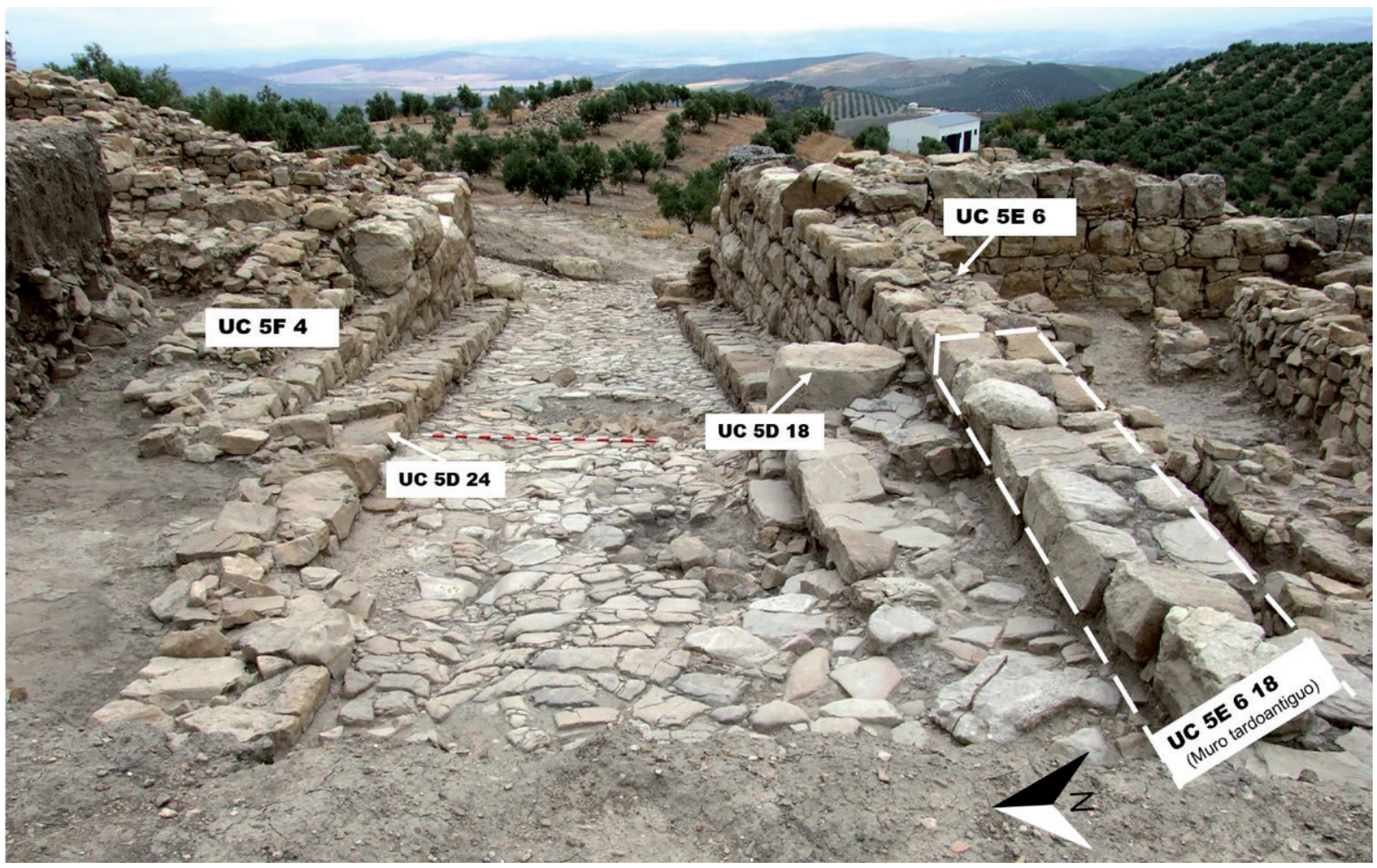

Figura 7. Vista del viario desde el interior de la ciudad y los muros que lo delimitan hasta la segunda puerta, marcada por el jalón, y restos de sus quicialeras, con indicación de las principales unidades mencionadas en el texto (Imagen cedida por J.A. Morena).

manera, las estructuras del acceso romano quedan integradas en una muralla de cronología anterior que seguirá en uso hasta el fin de la ocupación del yacimiento. Por tanto, se produce una dinámica similar a la observable en El Molón (Camporrobles, Valencia) donde gran parte de las defensas se remontan al siglo IV a.C., pero la puerta principal sufre importantes remodelaciones en los siglos II-I a.C. (Lorrio 2007).

\subsection{Los materiales}

Conocida esta secuencia que ofrece una cronología relativa, cabe profundizar en el momento preciso en el que se lleva a cabo este programa constructivo. Para ello es preciso atender a los materiales localizados en el relleno de los compartimentos de las torres y en su zanja de cimentación, ya que son contextos que quedan sellados en el momento de erección de las mismas.

En 1990 ya se documentaron, en el interior de la torre sur, algunos fragmentos interesantes de cara a la cronología (Cunliffe y Fernández 1999: 120) como son un fragmento de la forma 36 de Lamboglia (fig 9.1) y un galbo también en campaniense A (fig 9.2), lo que nos lleva a los siglos II-I a.C. En campaniense B aparece un galbo, de una posible forma 5 de Lamboglia (fig. 9.3), datable por tanto en el I a.C. (Pérez Ballester 2008: 651) y destaca además la presencia de un fragmento del pico de una lucerna de barniz negro con decoración puntillada del tipo Dressel 2 (fig 9.4). La cronología de este último fragmento abarca el siglo I a.C. y parte del I d.C. (Ricci 1973: 182 y ss., Cunliffe y Fernández 1999: 22), si bien según Pavolini (1987: 145 ) las producciones en barniz negro de este tipo concreto de lucerna hallan sus límites cronológicos en los años 40-30 a.C.

Son materiales que ofrecen un horizonte cronológico de en torno al siglo I a.C., si bien los excavadores consideraron que estos fragmentos «podrían haber sido arrojados al interior [de los compartimentos de la torre sur] en cualquier momento después de la construcción de la torre» (Cunliffe y Fernández 1999: 72). Esta interpretación, que hoy sabemos que es errónea, sumada al hallazgo de algunos fragmentos de cerámica pintada en la zanja de cimentación de la torre sur, permitió a los excavadores datar la puerta en los siglos IV-III a.C., lo 


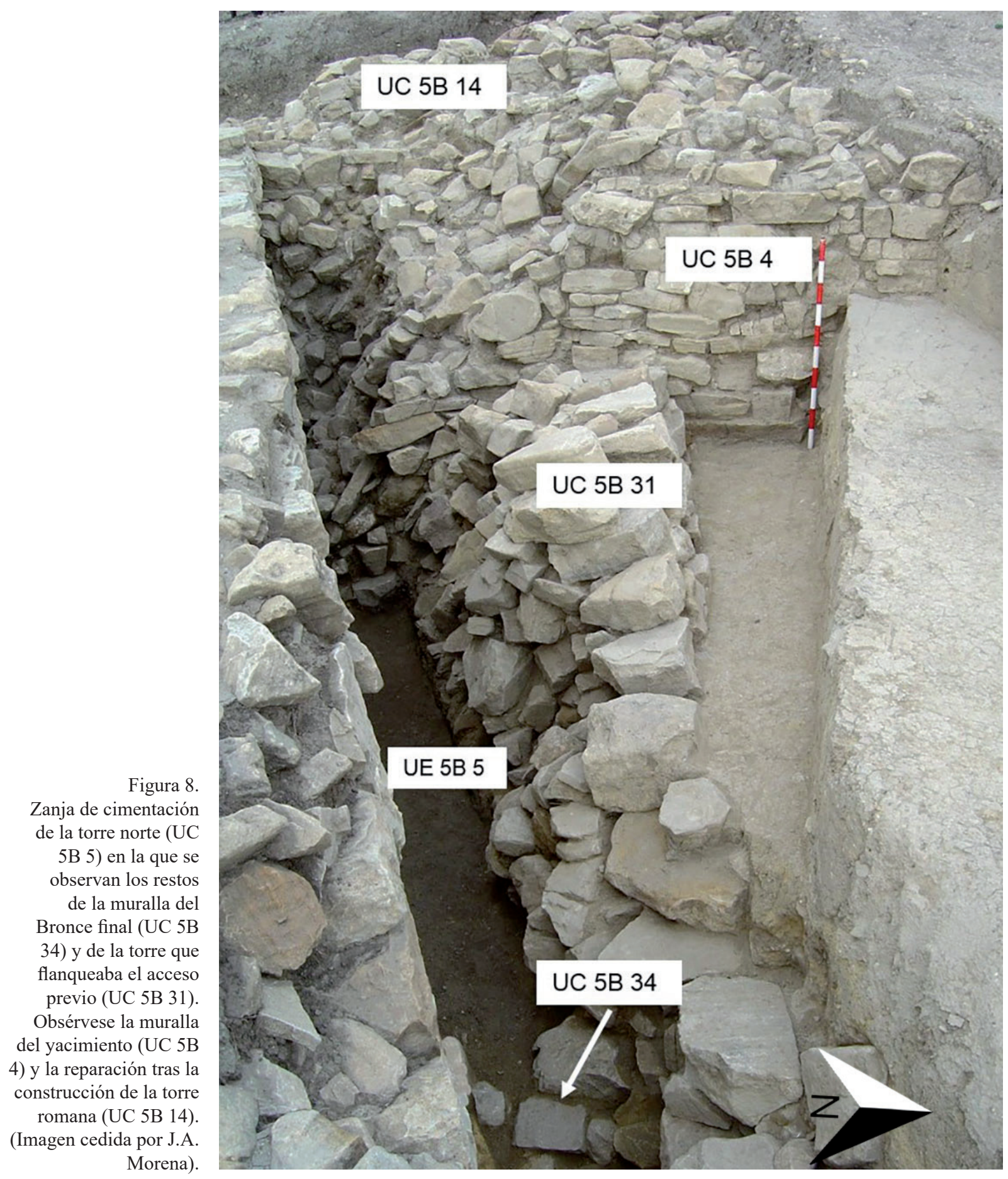

cual resultaba coherente con la secuencia cronológica que ellos propusieron para el yacimiento: un oppidum de época ibérica cuya ocupación finalizó en torno al cambio de era (Cunliffe y Fernández 1992: 237, Cunliffe y Fernández 1999: 72).
Sin embargo, las excavaciones que desde el año 2006 se han llevado a cabo en Torreparedones han permitido corroborar la continuidad del asentamiento en época romana imperial (Ventura 2014). Para el caso concreto de la datación de la puerta oriental, además de 


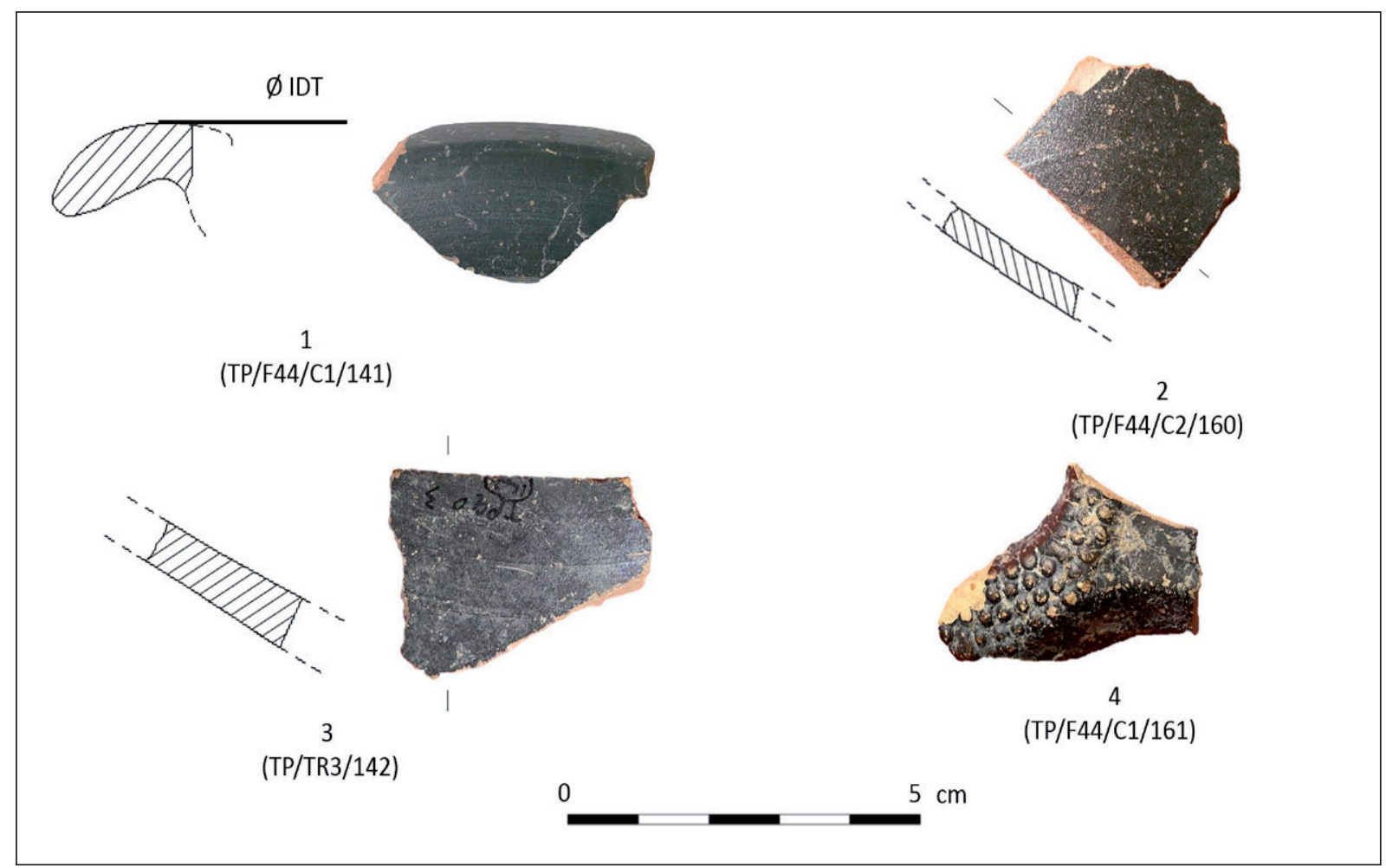

Figura 9. Materiales hallados en el interior de los compartimentos de la torre sur en la campaña de 1990 (fotografías y dibujos cedidos por A. Moreno).

los nuevos materiales hallados en 2006, se reconsideró la posición estratigráfica de los materiales exhumados por el Guadajoz Project (Morena 2010: 178). Estos no eran un término ante quem, como propusieron Cunliffe y Fernández (1999: 72), sino post quem: fragmentos bastante atomizados y rodados que se encontrarían en la tierra con la que se rellenaron las torres y sus zanjas de cimentación.

En cuanto a los materiales hallados en 2006, la torre norte ofrece poca información cronológica, pues su interior no se excava para evitar el deterioro de las estructuras, y los materiales hallados en el relleno de su zanja de cimentación (UE 5B 5) son escasos y no ofrecen una cronología precisa. Bastará con señalar que se trata principalmente de cerámica pintada y común, sin presencia de material campaniense, terra sigillata o paredes finas que nos acerquen a una datación concluyente. En cambio, en el caso de la torre sur el material es más destacable, comenzando porque, insertado en el propio muro oeste de la misma (UC 5E 3), se documenta un pequeño fragmento de pátera de campaniense beoide, de barniz compacto y pasta naranja oscura (fig 10.6), que nos lleva al I a.C.
En la zanja de cimentación (UE 5E 4) además de un fragmento muy rodado de un fondo de pátera ática, destaca la presencia de dos bordes de la forma 5 de Lamboglia, uno en campaniense A (fig. 10.1) y otro en B (fig 10.2), así como un galbo, posiblemente de esta misma forma, en campaniense B-beoide (fig 10.4). El plato o pátera Lamboglia 5 es una de las formas principales del repertorio de la campaniense $\mathrm{B}$, predominante en Hispania durante el siglo I a.C. (Principal y Ribera 2013: 49, Pérez Ballester 2008: 651 y ss.). Esa cronología puede proponerse también para el fragmento de esta forma en campaniense $\mathrm{A}$, en un contexto de producciones tardías en el que el repertorio de estas producciones se ve reducido y tiende a copiar formas desarrolladas por los talleres de la campaniense B (Adroher y López 1996: 114). Otro de los fragmentos presentes en este estrato es un fondo de cubilete de paredes finas sin engobe, posibles formas 1-4 de Mayet (fig 10.3), quizá 3.1 por el arranque de las paredes, cuya producción se extiende desde finales del siglo II a.C. hasta época augustea (López Mullor 2013).

Finalmente, podemos destacar la presencia en este estrato de un arranque de pico de una lucerna del tipo $\mathrm{H}$ 


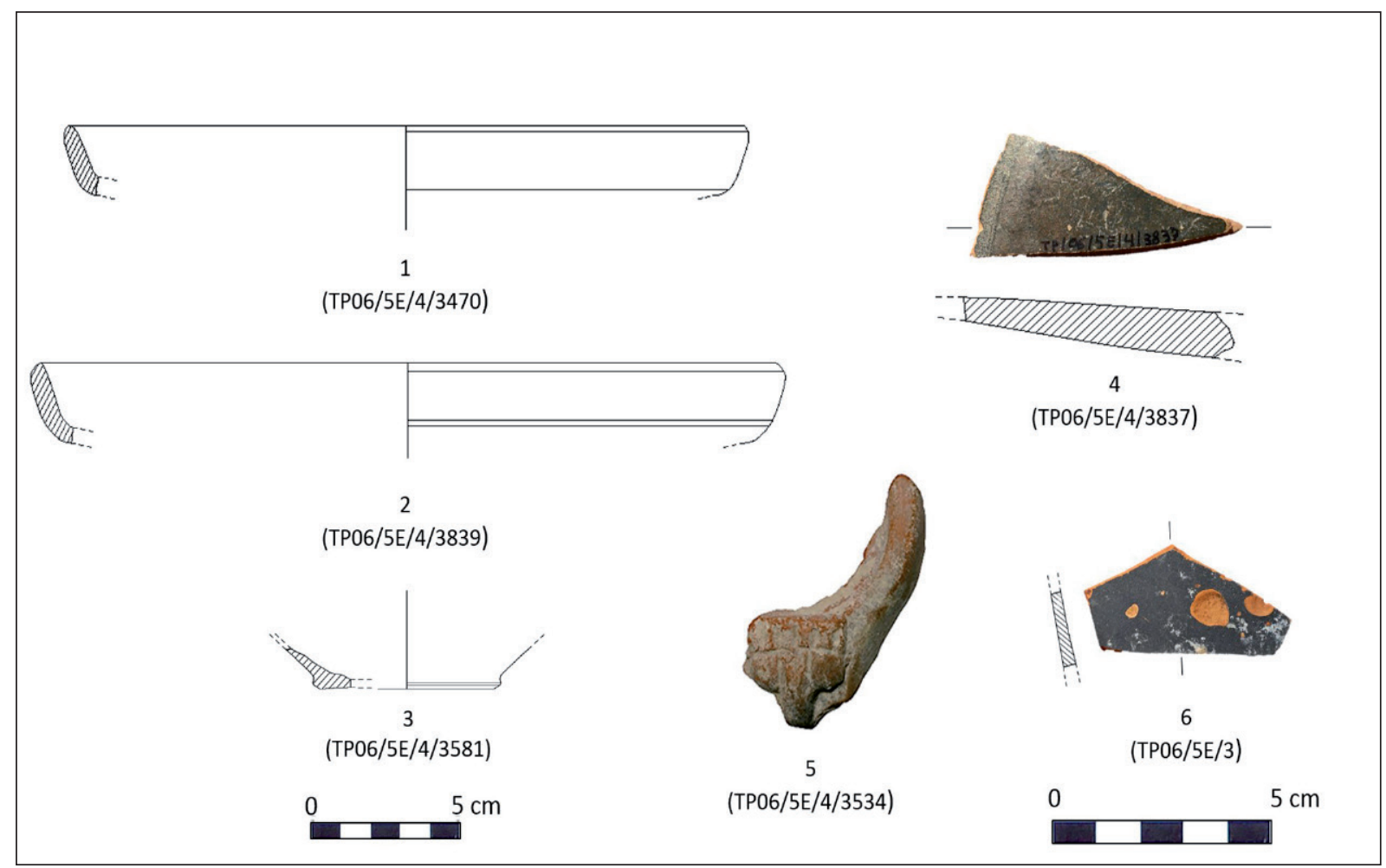

Figura 10. Materiales hallados en la zanja de cimentación de la torre sur (1-5) (UE 5E 4) y en el muro oeste de la misma (6) (UC 5E 3) en la campaña de 2006 (fotografías y dibujos cedidos por A. Moreno).

de Ricci (fig 10.5), producción habitual del siglo I a.C. que en Lucentum, por poner un ejemplo, aparece en contextos de entre el 40 a.C. y el cambio de era (García Barrachina 2016: 121). Este caso resulta especialmente interesante porque presenta decoración con un falo en relieve bajo una moldura de incisiones oblicuas, lo que tipológicamente permite catalogarla como una Phalluslampen de Ulbert (1984: 157). Estas lucernas, del tipo $\mathrm{H}$ de Ricci, pero realizadas a molde y con ese falo en relieve, son una producción local que procede del campamento sertoriano de Castra Caecilia (Cáceres el Viejo) (Ulbert 1984: 157).

En esta misma zanja de cimentación se localizó una moneda que ayuda a precisar la datación ofrecida por la cerámica (Pérez Tóvar 2013: 17). Se trata de un semis de la serie Sacerdos (fig. 11) (Burnett et al. 1992: 438, Villaronga 1994: 424), una emisión cuya ceca es bastante debatida en cuanto a su lugar de procedencia, pero datable con seguridad en el siglo I a.C., más concretamente en torno a los años 40-30 a.C. (Amela 2014 con bibliografía, Amela 2017: 403 y ss. con bibliografía, Villaronga y Benages 2011: 521). Tras estudiar la serie en profundidad, revisando y actualizando el debate historiográfico, Amela (2014 y 2017) concluye que es una amonedación que recuerda una fallida fundación colonial que Lépido encargó a Estatilio Libón, lo que le permite datarla en el 43-42 a.C. Sea como fuere, la práctica totalidad de autores coinciden en que se trata de una emisión del segundo triunvirato, enmarcable en un contexto preaugusteo (Arévalo et al. 2016: 900), a excepción de De Guadán (1969: 22) quien la sitúa tras la batalla de Actium (31 a.C.).

\subsection{Contexto}

En vista de la cronología aportada por los materiales, la puerta se puede datar en torno a la segunda mitad del siglo I a.C. (Morena 2010: 179, Moreno 2014: 40), en un contexto tardorrepublicano o quizá de comienzos del Imperio, en el que se dan una serie de circunstancias históricas interesantes que pudieron motivar la construcción de este nuevo acceso para la ciudad.

En ese sentido, cabe considerar en primer lugar la cercanía cronológica del Bellum Hispaniense (4645 a.C.), el enfrentamiento entre César y los hijos de 


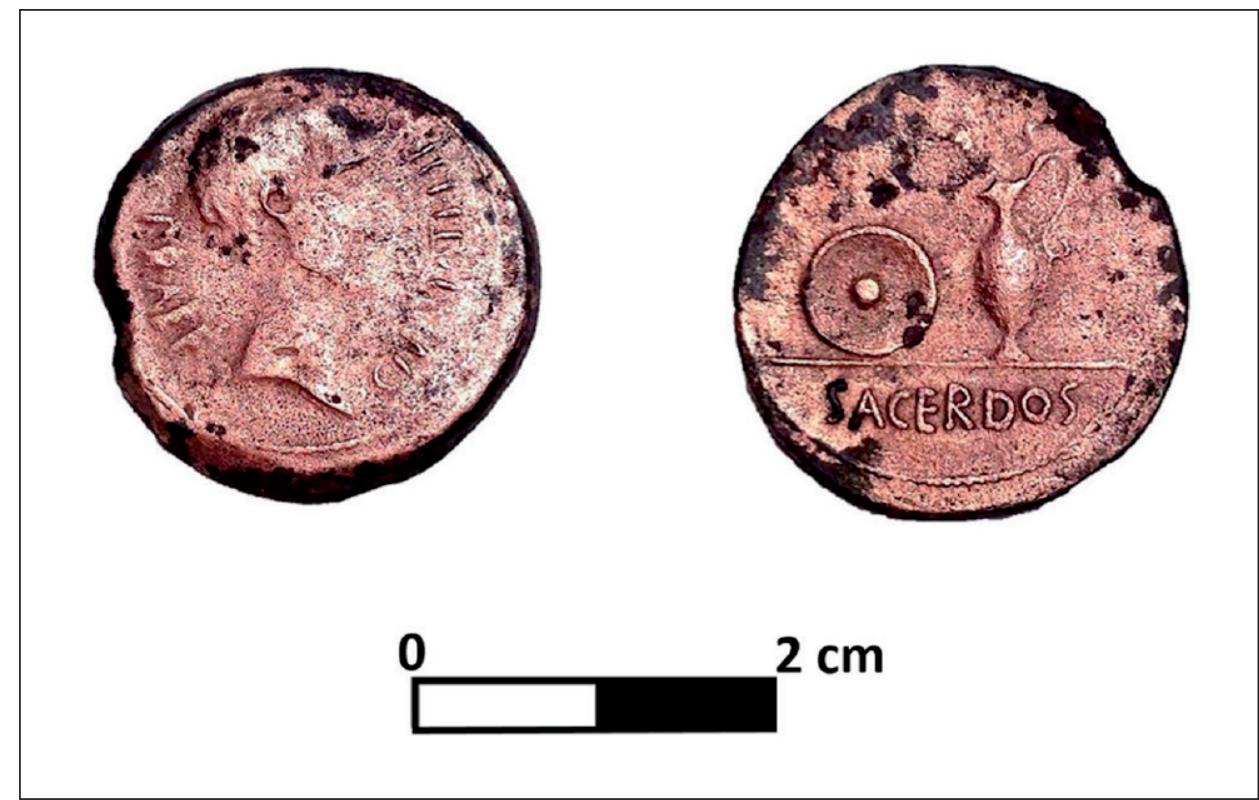

Figura 11.

Semis de la serie

Sacerdos hallado en la zanja de cimentación de la torre sur (UE 5E 4) (Imagen del autor).
Pompeyo que, con la batalla de Munda (45 a.C.), pondrá fin a la guerra civil. Se trata de un enfrentamiento ingens ac terribilis (Vel. Pat. II, 55) que se desarrolló en el entorno de este oppidum, pudiendo incluso sus habitantes participar en él (Rodríguez Neila 1988: 270, Morena 2010: 179). En ese sentido, se ha planteado que la puerta pudiera haberse construido para defender la ciudad en ese contexto (Morena 2010: 149, Morena y Moreno 2010: 441, Ventura 2014: 31, Moreno 2014: 40). Esta intencionalidad parece clara en otros casos, como es la puerta levantada en el 49 a.C. referida en una inscripción de La Rambla (Córdoba) (CIL II $2 / 5$, 521) (Stylow 2005: 255), pero no es tan evidente en el nuestro: el semis de la serie Sacerdos nos sitúa, como pronto, a finales de la década de los 40 a.C., momento posterior a la batalla de Munda (45 a.C.).

No obstante, no se puede descartar la influencia del Bellum Hispaniense, aun cuando la puerta fuese posterior al mismo y no se levantase como defensa en ese contexto bélico. Hay que tener en cuenta la cercanía del enfrentamiento y cómo, desde las propias murallas de Torreparedones, se pudieron contemplar episodios como el incendio de Ocubi (Espejo) (B.H. 27,4) o los cruentos sucesos de Ategua (B.H. 6-19). El vivo recuerdo de estos acontecimientos, sumado a las tensiones de las últimas décadas de la República y comienzos del Imperio, pudieron motivar el marcado carácter militar de la nueva puerta del asentamiento. Además, muchos de los colonos que en estos momentos llegan a la Bética, y a este propio yacimiento, son soldados veteranos (Ventura 2014: 32) entre los que pudieron encontrarse ingenieros militares que, como sugiere Morena (2010: 178), quizá participaron en este complejo proyecto.

Otra posibilidad es que la puerta se levantase en el contexto de una constitutio colonial que pudo tener lugar en torno a la década del 30 a.C. (Ventura 2012: 40, 2014: 32) tal vez de Virtus Iulia con la que se ha identificado a Torreparedones (Ventura 2012). Sin embargo, esta identificación está siendo revisada en la actualidad, debido al hallazgo de nuevos materiales epigráficos que apuntan a una identificación del asentamiento con un municipium Borense (Beltrán Fortes y Morena 2018: 34).

Por último, la puerta se enmarca en un contexto cronológico en el que se desarrolla un proceso generalizado de construcción de fortificaciones que, motivado por cambios en la realidad social que acontecen en el siglo I a.C., afecta al Mediterráneo en general en las últimas décadas de esta centuria (Gabba 1976). Se produce así una serie de reconfiguraciones y monumentalizaciones de numerosos accesos urbanos, vinculadas a cambios en las estructuras de poder y en el urbanismo y bien documentadas en yacimientos peninsulares (Del Reguero 2019: 229-230). Como ejemplo cercano en cuanto a cronología y localización se puede citar la puerta norte o "de los leones" de Cástulo, levantada en los siglos II-I a.C. aprovechando los restos de un templo púnico preexistente (Barba et al. 2015: 315). 


\section{SOBRE LA DEFENSA DE LA CIUDAD: FUNCIONAMIENTO Y TIPOLOGÍA DE LA PUERTA}

Más allá de esa monumentalidad y de todas las connotaciones ideológicas que adquieren los accesos urbanos, especialmente en el mundo antiguo, ha de tenerse en cuenta que forman parte de la muralla y como tal, desempeñan un importante papel en la defensa de la ciudad (Montanero y Asensio 2009: 177). Es más, una puerta es una "brecha" en el trazado murario por la que un enemigo puede adentrarse en las principales vías de la ciudad. Por ello, en los conjuntos de acceso se concentran una serie de sistemas y dispositivos que los dotan de capacidades defensivas, garantizando así la protección de un punto tan importante y sensible. En nuestro caso de estudio, dichas capacidades guardan plena relación con el sistema de control de paso, documentado a través de las estructuras conservadas. Este sistema consiste en que una vez que el enemigo traspase la primera puerta no entre directamente en la ciudad, sino que para ello tenga que llegar a la segunda, recorriendo esos $14.30 \mathrm{~m}$ de viario. La función por tanto de los muros de las torres y de esas fachadas que los continúan, no sería otra que la de evitar la dispersión de enemigos hacia el interior de la ciudad, generando así un angosto corredor entre ambas puertas. Además, como vemos en paralelos mediterráneos donde se ha conservado su desarrollo en altura, como es el caso de Side (Lawrence 1973: 327, McNicoll 1997: 147), estos muros presentan voladizos y parapetos en su parte superior que permiten someter el espacio del pasillo a un fuego cruzado.

Esa razón es la que explica la falta de cubrición del espacio entre las puertas, ya que dado el diseño del sistema defensivo, esto anularía la posibilidad de hostigar al enemigo una vez atraviese la primera puerta. Esas cubriciones son propias de las llamadas "torres portal", como las de la Bastida (Díes Cusí 2005), en las que la puerta es un edificio en sí mismo, una torre adelantada en el lienzo murario a través de la cual se accede a la ciudad (Sconfienza 2005: 18).

En cambio en este caso el tipo de acceso es diferente: las estructuras presentes y su funcionamiento permiten catalogar tipológicamente la puerta como "de tipo patio", también denominada cavedium o vorhoftor según la tipología de Brands (1988). Es cierto que en este caso no podemos hablar de un patio bien definido, con la característica morfología circular o cuadrangular presente en numerosos ejemplos mediterráneos, pero consideramos que se puede sostener esa adscripción tipológica porque el tramo de viario entre ambas puertas desempeña esa misma función. Algo similar ocurre en el caso helenístico de Priene, con un corredor de $6.05 \mathrm{~m}$ de ancho o en la Puerta de Nola de Pompeya, con dos puertas sobre un viario de $4.20 \mathrm{~m}$ de anchura (Brands 1988: 180 y ss.). En ese sentido, como paralelo peninsular podemos citar las defensas de Lucentvm, levantadas en el contexto del Bellum Hispaniense (Olcina 2002: 263), sobre cuyo viario se establece un sistema de contrapuertas que Olcina et al. (2014: 132) incluyen en el tipo vorhoftor, con la particularidad de que la distancia entre ambas puertas es bastante más reducida. Al igual que en nuestro caso, en estos tres conjuntos existen estructuras que permiten contener al enemigo y someterlo a un fuego cruzado.

Se trata de una solución defensiva conocida desde antiguo, empleada por ejemplo en la fortaleza nubia de Buhén (Émery et al. 1979). Es un modelo que evoluciona desde la puerta de tenaza, al añadir entre las torres o espolones delanteros una primera puerta alineada con una segunda situada con algunos metros más atrás (Montanero y Asensio 2009: 179). Su uso se generalizará desde el siglo IV a.C., siendo uno de los tipos de acceso más usados en el contexto del Mediterráneo helenístico (Winter 1971: 271, Montanero y Asensio 2009: 186), como se atestigua en numerosos casos de Asia Menor (McNicoll 1997), así como Grecia continental y la Magna Grecia (Winter 1971, Adam 1982). En este contexto de fortificaciones helenísticas, muchas de estas innovaciones defensivas, como es este modelo de puerta de patio, serán asumidas también por el mundo púnico. Así por ejemplo, en la puerta del barrio marítimo de Cartago aparece este sistema defensivo (Rakob 1998: 20, fig. 3).

Con todo, este modelo cobra especial relevancia en la república romana, pues en Italia existen numerosos casos de puertas de tipo "patio", recogidos por Brands (1988), y también es un sistema que se empleará en las grandes puertas urbanas de los últimos momentos de la República y los albores del Imperio, como las puertas Borsari y Dei Leoni (Verona) o la de Augusto en Nîmes. Para el caso concreto de la península ibérica, a la ya citada puerta de Lucentum podemos sumar otras cronológicamente cercanas a nuestro caso, como son las de Baelo Claudia, con el cavedium localizado en el espacio entre las torres (Sillières 1997: 81). Otro ejemplo destacable es la puerta de Sevilla en Carmona que, en su fase romana de en torno al cambio de era, se constituye como un acceso de tipo patio (Jiménez 1989: 187, Schattner 2005: 91). También en Itálica y Munigua (Schattner 2003) aparece esta tipología (Robles et al.: e.p. para un análisis detenido de 
los paralelos). Continuando con el sistema defensivo de la puerta oriental de Torreparedones, hemos de señalar que hasta la fecha no se han encontrado poternas en el entorno inmediato de este acceso, pues apenas se han excavado los sectores de muralla más próximos a esta puerta. No obstante, la ausencia de las mismas es habitual en las puertas de esta tipología, cuya estrategia defensiva consiste en que: «El enemigo debe acudir al defensor, que no habría salido de sus murallas sino que estaría esperando que el atacante entrase en estas "zonas de matanza": en primer lugar el área frente a la puerta, saturado por el ataque de la artillería y en segundo lugar, por el acceso en forma de patio» (McNicoll 1997: 147)

Así pues, en el estado actual de la cuestión, la puerta oriental de Torreparedones se puede describir como un sistema defensivo de carácter estático y "semi-activo", según el esquema de Pimouget-Pédarros (2000: 37). Esto se debe a que aunque se haga uso de la artillería para defender el frente, no existen elementos de contra-ofensiva.

Tampoco se ha localizado en el entorno de este acceso un foso, de hecho, ante las torres aparece una plataforma delantera enlosada que recibe el camino de acceso al oppidum. El foso es un recurso necesario para impedir el acercamiento del enemigo, y sobre todo de sus máquinas de asedio a la muralla, logrando evitar así labores de zapa (Aen. Tact, 37, 1). Únicamente en el entorno del santuario se identificó una zanja que tenía una profundidad de $3.5 \mathrm{~m}$, que fue interpretada como un posible foso defensivo (Cunliffe y Fernández 1999: 99, Fernández y Cunliffe 2002: 53, Morena 2018: 50), si bien Cunliffe y Fernández propusieron que podría tratarse de una zanja de cimentación para un edificio posterior.

\section{LAS TORRES COMO ELEMENTO DEFENSIVO: LA CUESTIÓN DE LA ARTILLERÍA}

Dentro de todo ese sistema las torres son uno de los elementos fundamentales para la defensa de la ciudad. En primer lugar porque su presencia permitiría «impresionar hasta la disuasión» (Quesada 2007: 76), manteniendo alejados a potenciales enemigos. Pero más allá de ese factor visual y disuasorio, las torres son estructuras imprescindibles para la defensa de la ciudad en general y de las puertas en particular. Resultan especialmente útiles en este tipo de puerta, ya que permitiría hostigar al enemigo que se encuentra en ese patio o pasillo y sobre todo, defender el frente de la ciudad mediante el empleo de una serie de máquinas de artillería.

Lamentablemente, hasta la fecha carecemos de evidencias materiales que permitan asegurar la presencia de estos dispositivos, como pudieran ser fragmentos de los bastidores y resortes, similares a los hallados en Caminreal (Teruel) (Vicente Redón et al. 1997), Ampurias (Bosch Gimpera 1914) o Azaila (Beltrán Lloris 1976: 181). Tampoco se han hallado restos de proyectiles como pudieran ser pila catapultaria o los bolaños de piedra que estas máquinas disparaban. La única, y posible, evidencia al respecto en este yacimiento procede del sector meridional de la muralla, donde Cunliffe y Fernández (1999: 44) identificaron una zanja realizada en el siglo I a.C. que penetraba $1.2 \mathrm{~m}$ por debajo del suelo contemporáneo, rellenada inmediatamente con arcilla. Los autores proponían que esta suerte de plataforma serviría para colocar máquinas de artillería, si bien Escacena (2002: 82) señala que no es una obra defensiva, sino la huella de la caída de los adobes que conformaban el cuerpo superior de la muralla.

A pesar de las nulas evidencias materiales, creemos contar con los indicios suficientes para señalar que en estas torres se emplazaron máquinas de artillería. Uno de ellos es el propio contexto de construcción que ofrece la nueva datación de la puerta. En el contexto del Ibérico Pleno que proponían Cunliffe y Fernández (1999) sería discutible abordar estas cuestiones. Esto es debido al debate entre aquellos autores que defienden la existencia de una guerra de asedio y de máquinas de artillería en un momento temprano de la cultura ibérica (Gracia 2000, Gracia 2001) frente a los que opinan que el empleo de esta maquinaria, y el desarrollo de ese tipo de guerra en general en la península ibérica, no es anterior a la llegada de los Barca (Quesada 2001, Moret 2001).

Sea como fuere, la nueva datación sitúa a la puerta hacia la segunda mitad del siglo I a.C., un momento en el que las máquinas de artillería cuentan ya con una larga tradición (Sáez Abad 2004) y son, especialmente en el caso del mundo romano, herramientas imprescindibles en cualquier operación de asedio (Sáez Abad 2003). Esta relevancia está reflejada en las fuentes históricas, no solo en aquellas que narran innumerables tomas de ciudades, sino también en tratados de poliorcética de autores como Herón, Bitón, Filón de Bizancio o Vitrubio -recogidos y analizados por Marsden (1971)- que han permitido ampliar el conocimiento acerca de la evolución de las características técnicas de las máquinas de artillería. A ello se han de sumar los numerosos hallazgos relacionados con esta 
maquinaria realizados en la península ibérica en general (García y Sáez 2007, Sáez 2004: 392 y ss.) y en esta provincia en particular, como son, por poner un ejemplo, los pila catapultaria recientemente hallados en Montemayor (Córdoba) pertenecientes al contexto del asedio de Ulia en el Bellum Hispaniense (Quesada y Moralejo: com. per).

Otro importante indicio lo encontramos en el hecho de que el zócalo de las torres sea macizo, lo que para Marsden (1969: 134) es una característica definitoria de las torres de artillería. Además en este caso cuentan con esos muros de riostra que, según numerosos autores, favorecen la presencia de máquinas de artillería. Por tanto, sobre ese zócalo, como se ha propuesto en algunas publicaciones acerca de la puerta (Moreno 2104: 42) es muy posible que existieran cámaras con esa maquinaria. Como señala Marsden (1969: 152), «sería un gasto absurdo si una cámara con aspilleras, construida con considerable esfuerzo y gasto a una altura suficiente sobre el nivel del suelo, no fuese usada para artillería y solo beneficiase al defensor cuando el enemigo hubiese alcanzado el pie de la ciudad».

El último indicio al respecto es la configuración defensiva del acceso: un sistema de tipo patio que precisa de artillería para reducir el número de enemigos que se aproximan hacia el interior del mismo, como señalaba McNicoll (1997: 147). Así pues, es posible asumir la presencia de estas máquinas en las torres que flanquean el acceso oriental, aunque la altura conservada no permita conocer las cámaras y sus características, como número, altura, grosor de muros y sobre todo la presencia y disposición de aspilleras y ventanas. Este último dato sería especialmente útil para conocer el número de máquinas ubicadas en su interior y reconstruir con precisión su disposición, como se ha hecho en otros casos (Ruiz de Arbulo 2007: 567-594).

La única manera de resolver esta cuestión es de manera teórica, partiendo de los datos excavados y estableciendo una serie de hipótesis sobre las torres y la maquinaria. Por ejemplo, con lo que respecta al zócalo, se pueden establecer dos hipótesis sobre las dimensiones de las cámaras (fig. 12):

- Hipótesis A: En esta propuesta se asume que el grosor del muro del alzado es el mismo que el del zócalo. Con ello, tendríamos unas cámaras con 3.95 $\mathrm{m}$ de frente y $6.28 \mathrm{~m}$ de lado en la torre norte y de $4.20 \mathrm{~m}$ de frente y $6.88 \mathrm{~m}$ de lado en la torre sur. Se trataría de cámaras de casi $30 \mathrm{~m}^{2}$ de superficie. Sin embargo, la dimensión de fachada efectiva para la apertura de aspilleras en los laterales es menor por el adosamiento de las murallas a las torres, que es de
$3.03 \mathrm{~m}$ en la torre norte y de $4.05 \mathrm{~m}$ en la torre sur, siendo por tanto ese espacio efectivo de $4.95 \mathrm{~m} \mathrm{y}$ de $4.53 \mathrm{~m}$ respectivamente. El problema de esta hipótesis es que la cámara tiene gran grosor de muro, lo que reduce en exceso el ángulo de tiro (Marsden 1969: 140) ya que las aberturas tendrían que cortar un muro de casi dos metros.

- Hipótesis B: Con esta hipótesis podemos suponer que el alzado de la torre es mucho más liviano y que sus muros pueden tener, teóricamente, un metro menos de anchura que el zócalo. Esto deja cámaras cuyos muros tendrían un ancho de $1 \mathrm{~m}$ y 0.7 $\mathrm{m}$, dimensiones acordes a los grosores de muro de numerosas cámaras de artillería (Adam 1982: 142 y Ss.). Con esta segunda propuesta, se permite un mejor ángulo de tiro y tendríamos unas máquinas de mayor tamaño: $5.95 \mathrm{~m}$ de frente y $8.28 \mathrm{~m}$ de lado en la torre norte, y en la torre sur $6.20 \mathrm{~m}$ de frente $\mathrm{y}$ $8.88 \mathrm{~m}$ de profundidad. Son cámaras con una superficie de en torno a $50 \mathrm{~m}^{2}$, más que suficiente para la introducción de esas máquinas de artillería No obstante, al igual que en el caso anterior hay que considerar la unión de la muralla con las torres, lo que deja un lateral efectivo de $5.95 \mathrm{~m}$ en la torre norte y $5.53 \mathrm{~m}$ en la torre sur.

Ahora bien, conocer el tipo de máquinas que existirían en estas torres es algo más complicado y que, dado el vacío de información existente, solo podremos abordar de manera teórica. Para ello partiremos de las hipótesis anteriores sobre las dimensiones de las cámaras y del espacio operacional que requiere cada máquina señalado por Bakhuizen (1992: 153), quien se basa en las medidas de los tipos de maquinaria propuestas por Marsden (1969: 34-36, 1971: 158), en sus estudios técnicos. Seguimos también esos volúmenes para la propuesta del peso de cada máquina. Es preciso tener en cuenta una serie de cuestiones de difícil solución con los datos actuales:

- Ubicación de las máquinas: La conservación de aspilleras podría haber solucionado este punto, ya que las mismas indicarían desde dónde se disparaba. No obstante, podemos considerar el frente de la torre como espacio prioritario para la colocación de las mismas y, en segundo lugar, también los flancos de las torres que se orientan hacia el exterior de la ciudad. Aunque para valorar esa segunda posición sería preciso profundizar en el desarrollo arquitectónico y constructivo de la muralla, pues a 48 m y $38 \mathrm{~m}$ de esta puerta, dentro del trazado murario, aparecen dos torres o bastiones, las llamadas 
“torres 6 y 7” por Cunliffe y Fernández (1999: 54), cuya ubicación pudo afectar al tiro, suponiendo que siguieran en uso contemporáneamente a la puerta.

- Número de máquinas: Esta es otra cuestión que las aspilleras hubieran ayudado a solventar. No obstante, podemos plantear la existencia de hasta dos máquinas por flanco, puesto que este el número habitual en las torres (Marsden 1969: 141). Y es que hay que tener en cuenta que, aunque quepan 4 catapultas en un flanco sin solape de sus áreas operacionales, no significa que necesariamente existiesen cuatro catapultas en el mismo.

- Disposición de las máquinas: En caso de que existiera más de una máquina por flanco, no sabemos si se colocaban en el centro de la fachada o hacia los laterales de las mismas. Desconocemos también la distancia entre las máquinas y entre estas y las paredes laterales, así como si se colocaban en perpendicular a la fachada o en diagonal. Podemos resolverlo teóricamente planteando una separación isométrica entre las máquinas, así como entre las máquinas y las paredes laterales al frente que cubren. No hemos considerado tampoco la posibilidad de que se colocasen en posición oblicua, sino que como es un cálculo orientativo, solo hemos contemplado la posibilidad de que se alojasen en perpendicular al frente que defienden.

Considerando estos factores y las dimensiones del espacio operacional anteriormente mencionados, estamos en disposición de realizar una serie de cálculos que permitan comprobar si espacialmente es posible que estas torres alojasen máquinas de artillería. Aunque basados en cálculos metrológicos rigurosos, reconocemos el carácter especulativo de estos cálculos. Sin embargo, su objetivo no es el de señalar con precisión cuántas máquinas existían en cada torre, ni tampoco saber de qué tipo eran y cómo se disponían, algo que se puede realizar en aquellos casos donde las torres presentan un mayor estado de conservación. Se trata, en cambio, de comprobar si espacialmente estas torres permitían el alojamiento de máquinas de artillería, teniendo en cuenta su contexto y características constructivas. Los cálculos suponen por tanto un ensayo, una embrionaria propuesta metodológica que nos permitirá discernir si pudo o no existir artillería en aquellos casos donde por contexto y arquitectura es posible, pero no se conserva evidencia material al respecto.

Para ello, primero restaremos al frente de la cámara la suma de los anchos operacionales de las máquinas que consideremos. Para obtener la separación entre los espacios operacionales, que de manera orientativa hemos considerado isométrica, dividiremos el resultado de la resta anterior entre el número total de espacios existentes entre los espacios operacionales entre las máquinas y entre estas y la pared. Si este número es superior a cero, se puede considerar que no habrá solapamiento entre las mismas. Una vez calculado el frente, restamos al espacio útil del lateral de la cámara el largo operacional de las máquinas, para calcular así el espacio que sería funcional sin que hubiera solapamiento entre las partes traseras de las mismas de ambos flancos. Conocida esta dimensión, se repite aquí el mismo procedimiento que en el frente para conocer las que habría en cada lateral. Finalmente, multiplicamos el número total de las máquinas por el peso de cada una de ellas para saber el peso total del conjunto.

A modo de ejemplo, si prestamos atención al primer registro de la tabla 1: hemos considerado que al frente de la torre norte hay dos oxybeleis de un codo de calibre. Por tanto, se resta al espacio útil $(3.95 \mathrm{~m})$ el ancho operacional de estos dos dispositivos $(0.87 \mathrm{~m} \mathrm{x}$ 2) lo que resulta en $2.21 \mathrm{~m}$ sin ocupar. Ese resultado se divide entre el número de espacios entre ambas y entre las máquinas y la pared, que son 3 en este caso, lo que da de resultado $0.74 \mathrm{~m}$. Luego, al espacio útil del lateral $(4.95 \mathrm{~m})$ le restamos el largo del espacio operacional que requieren estos dispositivos de un codo situadas al frente $(1.54 \mathrm{~m})$ lo que deja libre un espacio de $3.41 \mathrm{~m}$. A eso le restamos el ancho de dos máquinas de un codo, lo que resulta $1.67 \mathrm{~m}$ que, al igual que para el frente, dividimos entre los tres espacios. Por último, multiplicamos el número total de oxybeleis/scorpiones por el peso de cada uno $(9.4 \mathrm{~kg}$.) lo que resulta en $37.6 \mathrm{~kg}$.

El resultado de estos cálculos son seis tablas de síntesis (tabs. 1-6), que si bien tienen carácter orientativo, cabe detenerse a analizar. Según estas, teóricamente caben máquinas del tipo scorpiones/oxybeleis (lanzadores de dardos) tanto considerando las dimensiones de la cámara de la hipótesis A (tabs. 1-2), como las de la B (Tablas 3-4). Si consideramos que todas las máquinas de la torre presentaban el mismo calibre, para cubrir ambos flancos se dispondría de máquinas de hasta dos codos. Aunque no es nuestra intención realizar aquí un completo análisis sobre la tipología de las máquinas y su balística, como los ya realizados por Marsden (1969) o Sáez Abad (2004 y 2005), cabe mencionar que este tipo de máquinas tienen un alcance máximo de 370 m (Marsden 1969: 86, Sáez Abad 2004: 506-507). Del mismo modo, en algunos 


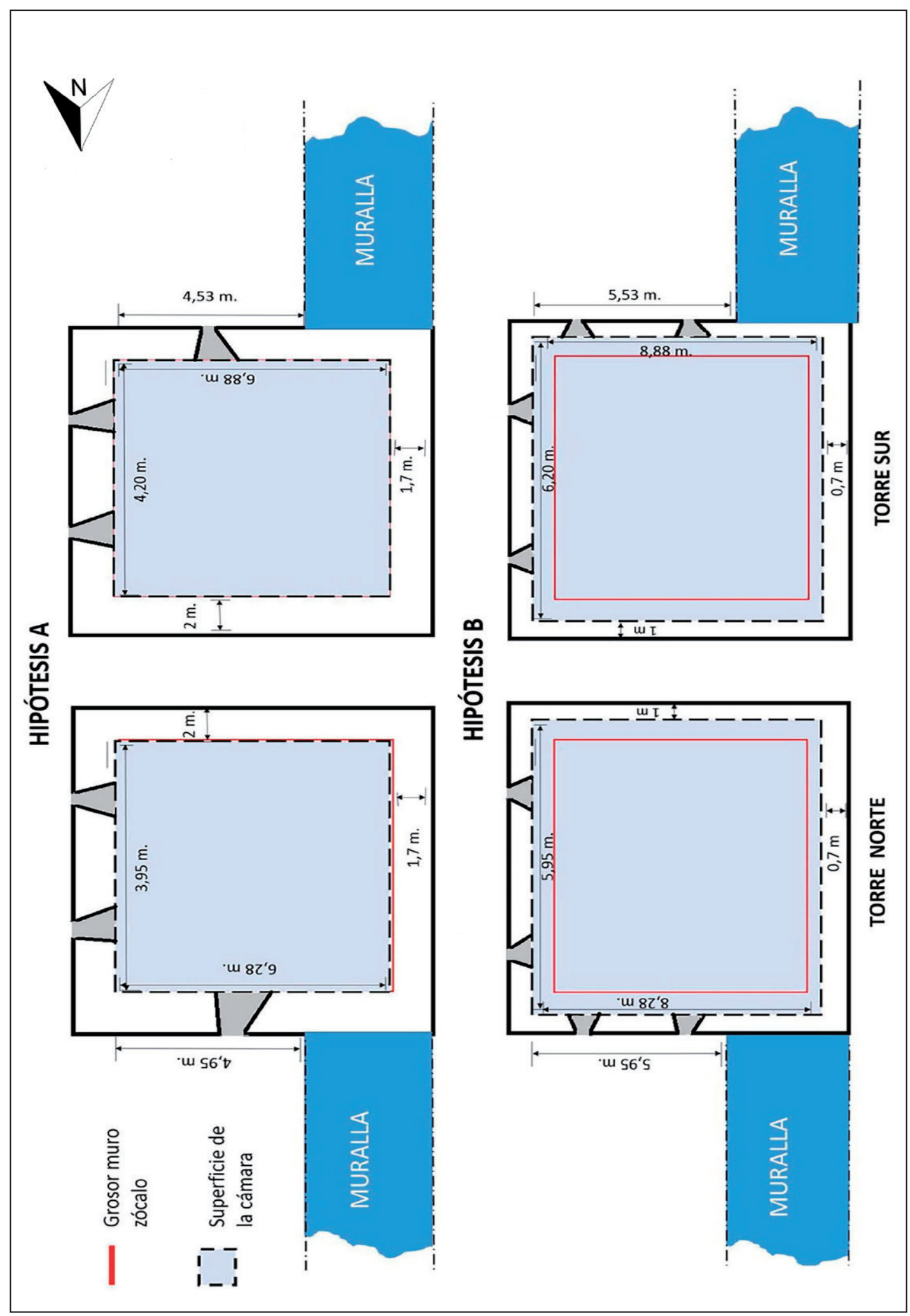

Figura 12. Esquema con las posibles dimensiones de las cámaras en alturas según las hipótesis referidas en el texto. Las aspilleras se han dibujado de manera orientativa como indicación de en qué lados se encontrarían. 
Tabla 1. Cálculos teóricos sobre el posicionamiento de oxybeleis/scorpiones en la torre norte según las dimensiones de la hipótesis A.

\begin{tabular}{|c|c|c|c|c|c|c|c|c|}
\hline Calibre & $\begin{array}{c}\text { Ancho } \\
\text { Operacional }\end{array}$ & $\begin{array}{c}\text { Largo } \\
\text { Operacional }\end{array}$ & $\begin{array}{c}\text { Máquinas } \\
\text { Alojables } \\
\text { Frente }\end{array}$ & $\begin{array}{c}\text { Separación } \\
\text { Espacio } \\
\text { Operacional } \\
\text { Frente }\end{array}$ & $\begin{array}{c}\text { Máquinas } \\
\text { Alojables } \\
\text { Lateral }\end{array}$ & $\begin{array}{c}\text { Separación } \\
\text { Espacio } \\
\text { Operacional } \\
\text { Lateral }\end{array}$ & $\begin{array}{c}\text { Máquinas } \\
\text { Totales } \\
\text { En Torre }\end{array}$ & $\begin{array}{c}\text { Peso } \\
\text { TOTAL }\end{array}$ \\
\hline 1 codo & $0.87 \mathrm{~m}$ & $1.54 \mathrm{~m}$ & 2 & $0.74 \mathrm{~m}$ & 2 & $0.56 \mathrm{~m}$ & 4 & $37.6 \mathrm{~kg}$ \\
\hline 3 palmos & $1.31 \mathrm{~m}$ & $2.32 \mathrm{~m}$ & 2 & $0.40 \mathrm{~m}$ & 1 & $0.67 \mathrm{~m}$ & 3 & $97.5 \mathrm{~kg}$ \\
\hline 2 codos & $1.75 \mathrm{~m}$ & $3.09 \mathrm{~m}$ & 2 & $0.15 \mathrm{~m}$ & 1 & $0.07 \mathrm{~m}$ & 3 & $237 \mathrm{~kg}$ \\
\hline 5 palmos & $2.19 \mathrm{~m}$ & $3.86 \mathrm{~m}$ & 1 & $0.88 \mathrm{~m}$ & $\begin{array}{l}\text { *Posibili- } \\
\text { dad de intro- } \\
\text { ducir máqui- } \\
\text { nas de los tres } \\
\text { calibres ante- } \\
\text { riores }\end{array}$ & - & 1 & $153 \mathrm{~kg}$ \\
\hline 3 codos & $2.62 \mathrm{~m}$ & $4.63 \mathrm{~m}$ & 1 & $0.67 \mathrm{~m}$ & - & - & 1 & $265 \mathrm{~kg}$ \\
\hline 7 palmos & $3.06 \mathrm{~m}$ & $5.40 \mathrm{~m}$ & 1 & $0.46 \mathrm{~m}$ & - & - & 1 & $422 \mathrm{~kg}$ \\
\hline 4 codos & $3.50 \mathrm{~m}$ & $6.18 \mathrm{~m}$ & 1 & $0.23 \mathrm{~m}$ & - & - & 1 & $630 \mathrm{~kg}$ \\
\hline
\end{tabular}

Tabla 2. Cálculos teóricos sobre el posicionamiento de oxybeleis/scorpiones en la torre sur según las dimensiones de la hipótesis A.

\begin{tabular}{|c|c|c|c|c|c|c|c|c|}
\hline Calibre & $\begin{array}{c}\text { Ancho } \\
\text { Operacional }\end{array}$ & $\begin{array}{c}\text { Largo } \\
\text { Operacional }\end{array}$ & $\begin{array}{c}\text { Máquinas } \\
\text { Alojables } \\
\text { Frente }\end{array}$ & $\begin{array}{c}\text { Separación } \\
\text { Espacio } \\
\text { Operacional } \\
\text { Frente }\end{array}$ & $\begin{array}{c}\text { Máquinas } \\
\text { Alojables } \\
\text { Lateral }\end{array}$ & $\begin{array}{l}\text { Separación } \\
\text { Espacio } \\
\text { Operacional } \\
\text { Lateral }\end{array}$ & $\begin{array}{c}\text { Máquinas } \\
\text { Totales } \\
\text { En Torre }\end{array}$ & $\begin{array}{c}\text { Peso } \\
\text { TOTAL }\end{array}$ \\
\hline 1 codo & $0.87 \mathrm{~m}$ & $1.54 \mathrm{~m}$ & 2 & $0.82 \mathrm{~m}$ & 2 & $0.42 \mathrm{~m}$ & 4 & $37.6 \mathrm{~kg}$ \\
\hline 3 palmos & $1.31 \mathrm{~m}$ & $2.32 \mathrm{~m}$ & 2 & $0.79 \mathrm{~m}$ & 1 & $0.45 \mathrm{~m}$ & 3 & $97.5 \mathrm{~kg}$ \\
\hline 2 codos & $1.75 \mathrm{~m}$ & $3.09 \mathrm{~m}$ & 2 & $0.35 \mathrm{~m}$ & $\begin{array}{l}\text { *Posiblidad de } \\
\text { introducir una } \\
\text { máquina de un } \\
\text { codo }\end{array}$ & - & 2 & $158 \mathrm{~kg}$ \\
\hline 5 palmos & $2.19 \mathrm{~m}$ & $3.86 \mathrm{~m}$ & 1 & $1.00 \mathrm{~m}$ & - & - & 1 & $153 \mathrm{~kg}$ \\
\hline 3 codos & $2.62 \mathrm{~m}$ & $4.63 \mathrm{~m}$ & 1 & $0.79 \mathrm{~m}$ & - & - & 1 & $265 \mathrm{~kg}$ \\
\hline 7 palmos & $3.06 \mathrm{~m}$ & $5.40 \mathrm{~m}$ & 1 & $0.57 \mathrm{~m}$ & - & - & 1 & $422 \mathrm{~kg}$ \\
\hline 4 codos & $3.50 \mathrm{~m}$ & $6.18 \mathrm{~m}$ & 1 & $0.35 \mathrm{~m}$ & - & - & 1 & $630 \mathrm{~kg}$ \\
\hline
\end{tabular}

casos las máquinas de calibres superiores al frente permiten la presencia de máquinas de calibres inferiores en los laterales.

En cuanto a las máquinas de tipo ballistae/lithoboloi (lanzadores de piedra), su alojamiento es más complejo dado su mayor tamaño: estos solo podrían alojarse si se diera la hipótesis B, pudiendo albergar estas cámaras máquinas de hasta 20 minas de calibre (tabs. 5-6). Estas solo podrían cubrir el frente dado que exceden la longitud de los laterales. Estas máquinas tienen un mayor peso que los oxybeleis, por lo que su presencia podría justificar el uso de las cruces internas de acuerdo con lo anteriormente expuesto (vid. supr.).

Aunque ambas hipótesis son plausibles, la opción $\mathrm{B}$ resulta más favorable, ya que permite arrojar mayor 
Tabla 3. Cálculos teóricos sobre el posicionamiento de oxybeleis/scorpiones en la torre norte según las dimensiones de la hipótesis B.

\begin{tabular}{|c|c|c|c|c|c|c|c|c|}
\hline Calibre & $\begin{array}{c}\text { Ancho } \\
\text { Operacional }\end{array}$ & $\begin{array}{c}\text { Largo } \\
\text { Operacional }\end{array}$ & $\begin{array}{c}\text { Máquinas } \\
\text { Alojables } \\
\text { Frente }\end{array}$ & $\begin{array}{l}\text { Separación } \\
\text { Espacio } \\
\text { Operacional } \\
\text { Frente }\end{array}$ & $\begin{array}{c}\text { Máquinas } \\
\text { Alojables } \\
\text { Lateral }\end{array}$ & $\begin{array}{l}\text { Separación } \\
\text { Espacio } \\
\text { Operacional } \\
\text { Lateral }\end{array}$ & $\begin{array}{l}\text { Máquinas } \\
\text { Totales } \\
\text { En Torre }\end{array}$ & $\begin{array}{c}\text { Peso } \\
\text { TOTAL }\end{array}$ \\
\hline 1 codo & $0.87 \mathrm{~m}$ & $1.54 \mathrm{~m}$ & 2 & $1.40 \mathrm{~m}$ & 2 & $0.89 \mathrm{~m}$ & 4 & $37.6 \mathrm{~kg}$ \\
\hline 3 palmos & $1.31 \mathrm{~m}$ & $2.32 \mathrm{~m}$ & 2 & $1.11 \mathrm{~m}$ & 1 & $0.63 \mathrm{~m}$ & 4 & $\begin{array}{l}130 \\
\mathrm{~kg}\end{array}$ \\
\hline 2 codos & $1.75 \mathrm{~m}$ & $3.09 \mathrm{~m}$ & 2 & $0.82 \mathrm{~m}$ & 1 & $0.56 \mathrm{~m}$ & 3 & $237 \mathrm{~kg}$ \\
\hline 5 palmos & $2.19 \mathrm{~m}$ & $3.86 \mathrm{~m}$ & 1 & $0.52 \mathrm{~m}$ & $\begin{array}{l}\text { *Posibilidad de } \\
\text { introducir má- } \\
\text { quinas de los } \\
\text { tres calibres an- } \\
\text { teriores }\end{array}$ & - & 2 & $306 \mathrm{~kg}$ \\
\hline 3 codos & $2.62 \mathrm{~m}$ & $4.63 \mathrm{~m}$ & 1 & $0.26 \mathrm{~m}$ & $\begin{array}{l}\text { * Máquina de } \\
\text { un codo o de } \\
\text { tres palmos }\end{array}$ & - & 2 & $\begin{array}{l}530 \\
\mathrm{~kg}\end{array}$ \\
\hline 7 palmos & $3.06 \mathrm{~m}$ & $5.40 \mathrm{~m}$ & 1 & $1.45 \mathrm{~m}$ & - & - & 1 & $422 \mathrm{~kg}$ \\
\hline 4 codos & $3.50 \mathrm{~m}$ & $6.18 \mathrm{~m}$ & 1 & $1.23 \mathrm{~m}$ & - & - & 1 & $630 \mathrm{~kg}$ \\
\hline
\end{tabular}

Tabla 4. Cálculos teóricos sobre el posicionamiento de oxybeleis/scorpiones en la torre sur según las dimensiones de la hipótesis B.

\begin{tabular}{|c|c|c|c|c|c|c|c|c|}
\hline Calibre & $\begin{array}{c}\text { Ancho } \\
\text { Operacional }\end{array}$ & $\begin{array}{c}\text { Largo } \\
\text { Operacional }\end{array}$ & $\begin{array}{c}\text { Máquinas } \\
\text { Alojables } \\
\text { Frente }\end{array}$ & $\begin{array}{l}\text { Separación } \\
\text { Espacio } \\
\text { Operacional } \\
\text { Frente }\end{array}$ & $\begin{array}{c}\text { Máquinas } \\
\text { Alojables } \\
\text { Lateral }\end{array}$ & $\begin{array}{l}\text { Separación } \\
\text { Espacio } \\
\text { Operacional } \\
\text { Lateral }\end{array}$ & $\begin{array}{c}\text { Máquinas } \\
\text { Totales } \\
\text { En Torre }\end{array}$ & $\begin{array}{c}\text { Peso } \\
\text { TOTAL }\end{array}$ \\
\hline 1 codo & $0.87 \mathrm{~m}$ & $1.54 \mathrm{~m}$ & 2 & $1.49 \mathrm{~m}$ & 2 & $0.75 \mathrm{~m}$ & 4 & $37.6 \mathrm{~kg}$ \\
\hline 3 palmos & $1.31 \mathrm{~m}$ & $2.32 \mathrm{~m}$ & 2 & $1.19 \mathrm{~m}$ & 2 & $0.20 \mathrm{~m}$ & 4 & $130 \mathrm{~kg}$ \\
\hline 2 codos & $1.75 \mathrm{~m}$ & $3.09 \mathrm{~m}$ & 2 & $0.9 \mathrm{~m}$ & 1 & $0.35 \mathrm{~m}$ & 3 & $237 \mathrm{~kg}$ \\
\hline 5 palmos & $2.19 \mathrm{~m}$ & $3.86 \mathrm{~m}$ & 2 & $0.61 \mathrm{~m}$ & $\begin{array}{l}\text { *Posibilidad de } \\
\text { introducir má- } \\
\text { quina de un } \\
\text { codo o de tres } \\
\text { palmos }\end{array}$ & - & 2 & $306 \mathrm{~kg}$ \\
\hline 3 codos & $2.62 \mathrm{~m}$ & $4.63 \mathrm{~m}$ & 2 & $0.32 \mathrm{~m}$ & $\begin{array}{l}\text { *Máquina de } \\
\text { un codo }\end{array}$ & - & 1 & $530 \mathrm{~kg}$ \\
\hline 7 palmos & $3.06 \mathrm{~m}$ & $5.40 \mathrm{~m}$ & 1 & $1.57 \mathrm{~m}$ & - & - & 1 & $422 \mathrm{~kg}$ \\
\hline 4 codos & $3.50 \mathrm{~m}$ & $6.18 \mathrm{~m}$ & 1 & $1.35 \mathrm{~m}$ & - & - & 1 & $630 \mathrm{~kg}$ \\
\hline
\end{tabular}

número de oxybeleis/scorpiones y es la única que permitiría alojar lithoboloi/ballistae, así como obtener mejor ángulo de tiro. Cabe considerar la posibilidad de que cada torre tuviera no una sino dos cámaras, viéndose favorecidas las superiores por una mayor altura que permite un incremento en el espacio operacional y el alcance de los proyectiles (Bakhuizen 1992: 142). En cualquier caso, a los indicios arquitectónicos y contextuales se han de añadir las evidencias espaciales que permiten suponer que aquí pudieron existir máquinas de artillería que ayudarían a defender el frente y los laterales de este acceso. 
Tabla 5. Cálculos teóricos sobre el posicionamiento de lithoboloi en la torre norte según las dimensiones de la hipótesis B.

\begin{tabular}{|c|c|c|c|c|c|c|c|c|}
\hline Calibre & $\begin{array}{c}\text { Ancho } \\
\text { Operacional }\end{array}$ & $\begin{array}{c}\text { Largo } \\
\text { Operacional }\end{array}$ & $\begin{array}{c}\text { Máquinas } \\
\text { Alojables } \\
\text { Frente }\end{array}$ & $\begin{array}{l}\text { Separación } \\
\text { Espacio } \\
\text { Operacional } \\
\text { Frente }\end{array}$ & $\begin{array}{c}\text { Máquinas } \\
\text { Alojables } \\
\text { Lateral }\end{array}$ & $\begin{array}{c}\text { Separación } \\
\text { Espacio } \\
\text { Operacional } \\
\text { Lateral }\end{array}$ & $\begin{array}{c}\text { Máquinas } \\
\text { Totales } \\
\text { En Torre }\end{array}$ & $\begin{array}{c}\text { Peso } \\
\text { TOTAL }\end{array}$ \\
\hline 10 minas & $3.18 \mathrm{~m}$ & $6.37 \mathrm{~m}$ & 1 & $1.39 \mathrm{~m}$ & 1 & $813 \mathrm{~kg}$ & - & - \\
\hline 15 minas & $1.31 \mathrm{~m}$ & $7.29 \mathrm{~m}$ & 1 & $1.15 \mathrm{~m}$ & 1 & $\begin{array}{c}1219 \\
\mathrm{~kg}\end{array}$ & - & - \\
\hline 20 minas & $1.75 \mathrm{~m}$ & $8.02 \mathrm{~m}$ & 1 & $0.97 \mathrm{~m}$ & 1 & $1627 \mathrm{~kg}$ & - & - \\
\hline
\end{tabular}

Tabla 6. Cálculos teóricos sobre el posicionamiento de lithoboloi en la torre sur según las dimensiones de la hipótesis B.

\begin{tabular}{|c|c|c|c|c|c|c|c|c|}
\hline Calibre & $\begin{array}{c}\text { Ancho } \\
\text { Operacional }\end{array}$ & $\begin{array}{c}\text { Largo } \\
\text { Operacional }\end{array}$ & $\begin{array}{c}\text { Máquinas } \\
\text { Alojables } \\
\text { Frente }\end{array}$ & $\begin{array}{l}\text { Separación } \\
\text { Espacio } \\
\text { Operacional } \\
\text { Frente }\end{array}$ & $\begin{array}{c}\text { Máquinas } \\
\text { Alojables } \\
\text { Lateral }\end{array}$ & $\begin{array}{c}\text { Separación } \\
\text { Espacio } \\
\text { Operacional } \\
\text { Lateral }\end{array}$ & $\begin{array}{l}\text { Máquinas } \\
\text { Totales } \\
\text { En Torre }\end{array}$ & $\begin{array}{c}\text { Peso } \\
\text { TOTAL }\end{array}$ \\
\hline 10 minas & $3.18 \mathrm{~m}$ & $6.37 \mathrm{~m}$ & 1 & $1.51 \mathrm{~m}$ & 1 & $813 \mathrm{~kg}$ & - & - \\
\hline 15 minas & $1.31 \mathrm{~m}$ & $7.29 \mathrm{~m}$ & 1 & $1.28 \mathrm{~m}$ & 1 & $\begin{array}{c}1219 \\
\mathrm{~kg}\end{array}$ & - & - \\
\hline 20 minas & $1.75 \mathrm{~m}$ & $8.02 \mathrm{~m}$ & 1 & $1.10 \mathrm{~m}$ & 1 & $1627 \mathrm{~kg}$ & - & - \\
\hline
\end{tabular}

\section{CONCLUSIONES}

Hacia el comienzo de la segunda mitad del siglo I a.C. se lleva a cabo en Torreparedones un programa constructivo con el que se levanta una de las puertas principales, o quizá la principal, de este asentamiento. La construcción de este conjunto de acceso es una buena muestra de los cambios sociales y urbanos que en torno al cambio de era se producen en el Mediterráneo en general y en Hispania en particular.

En primer lugar, la puerta ha de entenderse dentro de una serie de cambios en el paisaje urbano: el acceso previo aquí existente se ve sustituido por un enorme complejo, que presenta una plataforma delantera, un efectivo sistema de control de paso y sobre todo, dos imponentes torres de aparejo casi ciclópeo. Estas torres serían visibles desde lejos, destacando sobre la muralla y convirtiéndose así en un símbolo de la ciudad como ya propuso Moret (1998: 91) para este caso concreto. En el mundo protohistórico y antiguo, las puertas y las fortificaciones no son solo una obra de arquitectura defensiva, sino también una verdadera manifestación de poder y de las capacidades constructivas, bélicas y económicas de aquellos que las han levantado (Berrocal Rangel 2004).
Estos cambios en el urbanismo afectan también al interior de la ciudad, pues la puerta se convierte en uno de los puntos fundamentales del entramado urbano de Torreparedones en época romana: de ella nace el decumanus maximus que recorre el asentamiento en sentido este-oeste y, tras atravesar el foro llega a la puerta occidental, identificada pero aún sin excavar. En ese sentido la puerta es fundamental para la articulación del nuevo urbanismo, en el que se incluye un foro y edificios públicos como termas, una curia o un templo entre otros (Pericet et al. 2017) y que parece tener su origen en torno al cambio de era.

Pero ante todo, es una puerta fortificada, un conjunto dotado de una serie de elementos defensivos que lo convierten en un acceso prácticamente infranqueable. Desde la llegada de las grandes potencias mediterráneas a nuestra península la forma de hacer la guerra, y en particular la de asedio, había experimentado una fuerte evolución. Se introdujeron así numerosos avances que, en el momento de construcción de esta puerta ya habían cristalizado, entre los que se encuentran los dispositivos de asedio y las máquinas de artillería. Buena prueba de esa "cristalización" son los numerosos episodios de asedio que ocurrieron en el marco del 
Bellum Hispaniense y que sacudieron el entorno inmediato de Torreparedones entre el 46-45 a.C. Estas formas de combatir y de tomar ciudades poco o nada tienen que ver con los enfrentamientos o razzias que los pueblos ibéricos mantuvieron en los siglos precedentes.

Consecuentemente, las defensas urbanas también evolucionan para responder a las innovaciones ofensivas. Nacen así sistemas como el aquí presente: una puerta de tipo "patio", modelo ampliamente difundido en el contexto de la poliorcética mediterránea con el que se protege el acceso creando una auténtica trampa para el enemigo. Además, las torres que flanquean ese acceso estarían equipadas con máquinas de artillería imprescindibles para saturar el frente de la ciudad en caso de ataque. Aunque no hayamos conservado evidencias físicas al respecto, el contexto en el que se crea este nuevo acceso, sus características de funcionamiento, constructivas y metrológicas parecen apuntar en ese sentido.

Es, en definitiva, un conjunto fortificado, probablemente posterior al Bellum Hispaniense, que desempeña un papel fundamental para la defensa de la ciudad y es al mismo tiempo una importante obra urbana y emblemática. Esta dualidad, propia de múltiples accesos urbanos, está en plena consonancia con el contexto histórico y geográfico de la obra, que no es otro que el final de la República, momento de cambios y tensiones a nivel político y social. Estos cambios hallan su reflejo arquitectónico en el urbanismo de numerosas ciudades y especialmente, en su cara más externa: las fortificaciones y accesos.

En lo que atañe a Torreparedones, el estudio e interpretación de la puerta oriental supone un primer acercamiento a las defensas de la ciudad, más allá de las aproximaciones que Cunliffe y Fernández (1999) realizaron sobre el trazado murario del asentamiento y sus bastiones. Son por tanto varias las cuestiones por precisar para poder completar el análisis poliorcético de este yacimiento. La comprensión global de su sistema defensivo pasa inevitablemente por la documentación del desarrollo histórico y arquitectónico de su muralla, así como de otros accesos entre los que destaca el ya identificado acceso occidental. El estudio y la potencial excavación de estos sectores permitirán, en un futuro, solventar algunas de las muchas dudas pendientes, sugeridas en parte por el estudio de esta puerta.

\section{Agradecimientos}

Trabajo realizado en el marco del proyecto de $\mathrm{I}+\mathrm{D}+\mathrm{i}$ del Ministerio de Ciencia y Tecnología y Ministerio de
Educación y Ciencia Ciudades y complejos aristocráticos en la conquista romana de la Alta Andalucía. Nuevas perspectivas y programa de puesta en valor (Cerro de la Cruz y Cerro de la Merced, Córdoba) (HAR2017-82806-P) y del Grupo de Investigación consolidado Pólemos. Arqueología e Historia Militar y de la Guerra de la Universidad Autónoma de Madrid.

El autor quiere agradecer a Fernando Quesada, José Antonio Morena y Antonio Moreno la asesoría científica en el transcurso de esta investigación, así como la cesión de documentación arqueológica y gráfica. Igualmente agradecemos los comentarios y sugerencias de los revisores que han contribuido a mejorar este trabajo.

\section{BIBLIOGRAFÍA}

Adam, J.P. (1982): L'architecture militaire grecque. París, Picard.

Adroher, A. y López, A. (1996): "Las cerámicas de barniz negro. II. Cerámicas campanienses”. Florentia Iliberritana 7: 11-37

Amela, L. (2014): "La emisión denominada "Tipo Sacerdos". Acta Numismática 44: 149-157.

Amela, L. (2017): El segundo triunvirato en Hispania. Fuentes literarias y numismáticas. Tesis Doctoral, Universidad de Castilla la Mancha, Disponible en https://ruidera.uclm.es/xmlui/handle/10578/16473 (20 de mayo de 2020)Arévalo, A.; Blánquez, J. y Roldán Gómez, L. (2016): "El taller monetal de Carteia (San Roque, Cádiz): recientes testimonios arqueológicos", en P. Grañeda (ed.), Actas del XV Congreso Nacional de Numismática: 897-914. Madrid (2015), Madrid, Museo Arqueológico Nacional.

Asensio Esteban, J.A. (2006): "El gran aparejo en piedra en la arquitectura de época romana republicana de la provincia Hispania citerior: el opus siliceum y el opus quadratum". Saldvie 6: 117-159.

Bakhuizen, S.C. (1992): A greek city of the fourth century b.C. Roma, L'Erma di Bretschneider.

Barba, V.; Fernández, A. y Jiménez, Y. (2015): “La muralla de Cástulo y la Puerta de los Leones", en A. Ruiz y M. Molinos (eds.), Jaén, tierra íbera: 40 años de investigación: 305-322. Jaén, Universidad de Jaén

Barresi, P. (1991): "Sopravivenze dell'únità di misura púnica e suoi rapporti con il piede romano nell'Africa di età imperiale", en A. Mastino (coord.), L'Africa Romana. Atti del V Convegno di Studio: 479-503. Cagliari (1990), Sácer, Università degli studi di Sassari. 
Barresi, P. (2007): Metrologia punica. Lugano, Lumières internationales.

Beltrán Fortes, J. y Morena, J.A. (2018): “Dos nuevos monumenta de la necrópolis norte de Torreparedones". Archivo Español de Arqueología 91: 7-38. https://doi.org/10.3989/aespa.091.018.001 Beltrán Lloris, M. (1976): Arqueología e Historia de las ciudades antiguas del Cabezo de Alcalá de Azaila (Teruel). Zaragoza, Universidad de Zaragoza.

Berrocal-Rangel, L. (2004): "La defensa de la comunidad: sobre las funciones problemáticas de las murallas protohistóricas en la península ibérica". Gladius 34: 27-98. Berrocal-Rangel, L. y Moret, P. (2007): "Las fortificaciones protohistóricas de la Hispania céltica. Cuestiones a debate", en L. Berrocal-Rangel y P. Moret (coords.), Paisajes fortificados de la Edad del Hierro: las murallas protohistóricas de la meseta y de la vertiente atlántica en su contexto europeo. Actas del coloquio celebrado en la Casa de Velázquez: 15-34. Madrid (2006), Madrid, Casa de Velázquez.

Bosch Gimpera, P. (1914): "La catapulta de Ampurias". Anuari del Institut d'Estudis Catalans 5: 841-846. Brands, G. (1988): Republikanische Stadtore in Italien. Oxford, British Archaeological Reports.

Burnett, A.; Amandry, M. y Ripollés, P.P. (1992): Roman provincial coinage. From the dead of Caesar to the dead of Vitellius (44 b.C- 69 A.D.). Londres, The British Museum Press.

Campos, J.M. y Bermejo, J. (2017): "Los suburbios de Onoba Aestuaria: el área portuaria”, en S. Panzram (coord.), Oppidum-Civitas-Urbs: Städteforschung auf der Iberischen Halbinsel zwischen Rom und alAndalus: 739-766. Múnich, Lit.

Cordente Vaquero, F. (2001): Poliorcética romana: 218-73 a.C. Tesis Doctoral, Universidad Complutense de Madrid. Disponible en https://eprints.ucm. es/2326/ (12 de mayo de 2020).

Cunliffe, B. W y Fernández, M.C. (1999): The Guadajoz Project: Andalusia in the First Milennium B.C. I: Torreparedones and its Hinterland. Oxford, Oxford University Press.

Cunliffe, B.W. y Fernández, M.C. (1992): “Torreparedones, 1990". Anuario Arqueológico de Arqueología 1990: 234-239.

De Guadán, A.M. (1969): "Una nueva moneda de Tingis". Numisma 96-101: 9-23.

Del Reguero, J. (2019): "Reconfiguración y monumentalización de la puerta sur del oppidum oretano de El Cerro de las Cabezas (Valdepeñas, Ciudad Real) (ss. V-III a.C.). Cuadernos de Prehistoria y Arqueología de la Universidad Autónoma de
Madrid 45: 225-238. https://doi.org/10.15366/cupauam2019.45.008

Díes Cusí, E. (2005): “La Torre Portal y el Portal Torreado en las fortificaciones ibéricas. Estudio de las entradas Norte y Oeste de la Bastida de Les Alcusses (Moixent, Valencia)", Sagvntvm 37: 73-84. https://doi.org/10.7203/SAGVNTVM

Emery, W.B.; Millard, A. y Smith, H.S. (1979): The Fortress of Buhen: The Archaeological Report. Londres, Egypt Exploration Society.

Escacena, J.L. (2002): "Murallas fenicias para Tartessos: un análisis darwinista”. Spal 11: 69-105. http:// dx.doi.org/10.12795/spal.2002.i11.04.

Fernández, M.C. y Cunliffe, B. (2002): El yacimiento y el santuario de Torreparedones. Un lugar arqueológico preferente en la campiña de Córdoba. Oxford: British Archaeological Reports.

Gabba, E. (1976): Republican Rome, the army and the allies. Oxford, Oxford University Press.

García Barrachina, A. (2016): "Las lucernas republicanas de Lucentum (Tossal de Manises, Alacant". Lucentum 35: 117-140. https://doi.org/10.14198/LVCENTVM2016.35.06.

Gracia Alonso, F. (2000): “Análisis táctico de las fortificaciones ibéricas”. Gladius 20: 131-170.

Gracia Alonso, F. (2001): "Sobre fortificaciones ibéricas. El problema de la divergencia respecto al pensamiento único". Gladius 21: 155-166.

Hauschild, T. (1977): “Torre de Minerva (San Magín)", Boletín Arqueológico: órgano de la Real Sociedad Arqueológica Tarraconense 4: 133-140

Hauschild, T. (1985): “Ausgrabungen in der römischen Sadtmauer von Tarragona. Torre de Minerva (1979) und Torre de Cabiscol (1983)". Madrider Mitteilungen 26: 75-90.

Hauschild, T. (2006): "Die römischen Tore des 2. Jhs. v.Chr. in der Stadmauer von Tarragona", en T. Schattner y F. Valdés (eds.), Puertas de ciudades. Tipos arquitectónicos y forma artística: 153-172. Toledo (2003), Maguncia, Verlag Philipp von Zabern.

Ioppolo, G. (1967): “La tavola delle unitá di misura nel mercato augusteo di Leptis Magna". Quaderni d'archeologia della Lybia 5: 89-98.

Jiménez, A. (1989): La puerta de Sevilla en Carmona. Sevilla, Junta de Andalucía.

Karlsson, L. (1992): Fortification towers and masonry techniques in the hegemony of Syracuse, 405-211 b.C. Estocolmo, Instituti Romani Regni.

López Mullor, A. (2013): “Cerámicas de paredes finas republicana y augustea”, en A. Ribera, (ed.), 
Manual de cerámica romana. Del mundo helenístico al Imperio Romano: 149-190. Madrid, Museo Arqueológico Regional.

Lorrio, A.J. (2007): "El Molón (Camporrobles, Valencia) y su territorio: Fortificaciones y paisaje fortificado de un espacio de frontera", en L. Berrocal-Rangel y P. Moret (eds.), Paisajes fortificados de la Edad del Hierro. Las murallas protohistóricas de la Meseta y la vertiente atlántica en su contexto europeo. Actas del coloquio celebrado en la Casa de Velázquez: 213236. Madrid (2006), Madrid, Casa de Velázquez.

Lugli, G. (1957): La tecnica edilizia romana con particolare riguardo a Roma e Lazio. Roma, Bardi.

Maher, M.P. (2012): The fortification of Arkadian poleis in the classical and Hellenistic periods. Tesis doctoral, University of British Columbia. Disponible en https://open.library.ubc.ca > media > download > pdf (10 de mayo de 2020).

Maier, J. (2010): “El mausoleo de los Pompeyos en su contexto histórico e historiográfico", en J. Beltrán; J. Maier; J. Miranda; J.A. Morena López y P. Rodríguez (eds.), El Mausoleo de los Pompeyos de Torreparedones (Baena, Córdoba). Análisis historiográfico y arqueológico. Salsvm 1: 75-140. Baena, Ayuntamiento de Baena.

Marín Martínez, P.A. (2012): Fortificaciones y poliorcética en época Bárcida: los ejemplos de Sicilia y la Península Ibérica. Trabajo de Fin de Máster, Universidad Complutense de Madrid. Disponible en https://rodin.uca.es/xmlui/bitstream/handle/10498/17374/La\%20presencia\%20 B\%C3\%A1rcida\%20en\%201a\%20P.I..pdf (20 de mayo de 2020).

Marsden, E.W. (1969): Greek and Roman Artillery. Historical developments. Oxford, Oxford University Press.

Marsden, E.W. (1971): Greek and Roman Artillery. Technical treatises. Oxford, Oxford University Press.

McNicoll, A.W. (1997): Hellenistic fortifications from Aegean to the Euphrates. Oxford, Oxford University Press.

Montanero, D. (2008): "Los sistemas defensivos de origen fenicio-púnico del sureste peninsular (siglos VIII-III a.C.): nuevas interpretaciones", en B. Costa y J. H. Fernández (eds.), Arquitectura defensiva fenicio-púnica. XXII Jornadas de Arqueología fenicio-púnica: 91-114. Ibiza (2007), Ibiza, Museu Arqueològic d'Eivissa i Formentera.

Montanero Vico, D. y Asensio, D. (2009): "Puertas fortificadas del Mediterráneo: Orígenes y evolución”. Revista d'Arqueologia de Ponent 19: 177-204.
Monterroso-Checa, A.; Teixidó, T.; Gasparini, M.; Rodero, S.; Moreno, J.C. y Morena, J.A. (2019): "Use of remote sensing, geophysical techniques and archaeological excavations to define the Roman amphitheater of Torreparedones (Córdoba, Spain)". Remote sensing 11: 2937. Disponible en https:// www.mdpi.com/2072-4292/11/24/2937 (15 de mayo de 2020). https://doi.org/10.3390/rs11242937

Morena, J, A. (2010): “Investigaciones recientes en Torreparedones (Baena, Córdoba): Prospección geofísica y excavaciones en el Santuario y la Puerta Oriental" en J. Beltrán, J. Maier, J. Miranda, J.A. Morena López y P. Rodríguez (eds.), El Mausoleo de los Pompeyos de Torreparedones (Baena, Córdoba). Análisis historiográfico y arqueológico. Salsvm 1: 171- 208. Baena, Ayuntamiento de Baena.

Morena, J.A. (2018): Sincretismo religioso, prácticas rituales y sanación en el santuario iberorromano de Torreparedones (Baena, Córdoba). Salsvm 6-7. Baena, Ayuntamiento de Baena.

Morena, J.A. (2019): Las santas Nunilo y Alodia ¿Mártires Mozárabes Cordobesas? A propósito del descubrimiento y excavación de la ermita de las vírgenes de Castro el Viejo. Baena, Ayuntamiento de Baena.

Morena, J.A. y Moreno, A. (2010): “Apuntes sobre el urbanismo romano de Torreparedones", en Quinto Congreso de las Obras Públicas Romanas. Las técnicas y construcciones en la ingeniería romana: 429-460. Córdoba (2010), Córdoba, Fundación de la Ingeniería Técnica de Obras Públicas.

Morena, J.A.; Sánchez de la Orden, M. y García-Ferrer, A. (1990): Prospecciones geofisicas en la campiña de Córdoba. Córdoba, ETSIA Servicio de Publicaciones.

Moreno, A. (2014): "La puerta oriental”, en C. Márquez, J.A. Morena, A. Córdoba y A. Ventura (eds.), Torreparedones-Baena, Córdoba- Investigaciones Arqueológicas (2006-2012): 39-45. Córdoba, Ayuntamiento de Baena.

Moret, P. (1996): Les fortifications ibériques de la fin de l'âge du bronze à la conquête romaine. Madrid, Casa de Velázquez.

Moret, P. (1998): "Rostros de piedra. Sobre la racionalidad del proyecto arquitectónico de las fortificaciones urbanas ibéricas", en C. Aranegui (ed.), Los Iberos, Príncipes de Occidente. Actas del Congreso Internacional. Sagvntvm Extra $n^{\circ}$ 1: 83-92. Barcelona (1998), Valencia, Universidad de Valencia.

Moret, P. (2002): "Les fortifications ibériques complexes: questions de tracé et d'unité de mesure" en P. Moret y F. Quesada (eds.): La guerra en el mundo 
ibérico y celtibérico (ss. VI-II a. de C.). Actas del simposio: 189-215. Madrid (1996), Madrid, Casa de Velázquez.

Olcina, M. (2002): “Lucentum”, en J.L. Jiménez Salvador y A. Ribera i Lacomba (eds.), Valencia y las primeras ciudades romanas de Hispania: 255-266. Valencia, Ayuntamiento de Valencia.

Olcina, M.; Guilabert Mas, A.P. y Tendero Porras, E. (2014): "Las fortificaciones tardorrepublicanas de Lucentum (Hispania Citerior)", en F. Sala Sellés y J. Moratalla (eds.), Las guerras civiles en Hispania, una revisión desde la Contestania: 127-141. Alicante, Museo Arqueológico de Alicante.

Olmos Benlloch, P. (2010): Estudi dels patrons mètrics arquitectònics $i$ urbaístics del món ibèric (segles $V$-II $a . C$.). Tesis doctoral. Universitat Rovira i Virgil. Disponible en https:/www.tdx.cat/handle/1080 3/8641;jsessionid=B4DD58655F7371342CFC468 AA6477CC5 (22 de abril de 2019)

Pavolini, C. (1987): "La lucerne romane fra il III sec. a.C. e il III sec d.C.", en P. Lévêque y J.P. Morel (eds.), Cerámiques hellenistiques et romaines. II: 139-166. Paris, Les Belles Letres.

Pedersen, O. y Ruppe, U. (2016): "The fortifications at Halikarnassos and Priene: Some regional Characteristics?" en R. Frederiksen, S. Müth, P.I Schneider y M. Schnelle (eds.), Focus on Fortifications. New Research on Fortifications in the Ancient Mediterranean and the Near East: 560- 580. Londres, Oxbow Books.

Pedersen, P. (2010): "The city wall of Halicarnassus", en R. Van Bremen y J.M. Carbon (eds.) (2010), Hellenistic Karia. Proceedings of the First International Conference on Hellenistic: 269-316. Oxford, Oxford University Press.

Pérez Ballester, J. (2008): "Vajilla, gusto y consumo en la Carthago Nova republicana", en J. Uroz Sáez, J.M. Noguera y F. Coarelli (coords.), Iberia e Italia: modelos romanos de integración territorial. Actas del Congreso Histórico-Arqueológico Hispano-Italiano: 633-658. Murcia (2006), Murcia, Tabularium.

Pérez Tovar, M. J. (2013): "Selección de monedas halladas en el santuario y la puerta oriental de Torreparedones (Baena)". Ituci 3: 13-19.

Pericet, C.; Avilés, J.A.; Merino, A.; Muñoz Rodríguez, A.M. (2017): Estudios sobre la curia, el templo y las termas de la ciudad romana de Torreparedones (Baena Córdoba). Salsvm 4-5. Córdoba, Universidad de Córdoba.

Pimouguet-Pédarros, I. (2000): Archéologie de la défense: histoire des fortifications antiques de Carie (époques classique et hellénistique). París, Presses Universitaires Franc-Comtoises.

Pope, S. (2016): "Protection and Trade: Girding the city", en M.M. Miles (coord.), A companion to Greek Architecture: 254-272. Nueva York, Wiley.

Principal, J. y Ribera, A. (2013): “El material más apreciado por los arqueólogos. La cerámica fina. La cerámica de barniz negro", en A. Ribera (ed.), Manual de cerámica romana. Del mundo helenístico al Imperio Romano: 411-466. Madrid, Museo Arqueológico Regional.

Quesada, F. (2007): “Asedio, sitio, asalto... aspectos prácticos de la poliorcética en la Iberia prerromana”, en L. Berrocal-Rangel y P. Moret (coords.), Paisajes fortificados de la Edad del Hierro: las murallas protohistóricas de la meseta y de la vertiente atlántica en su contexto europeo. Actas del coloquio celebrado en la Casa de Velázquez: 75-98. Madrid (2006). Madrid, Casa de Velázquez.

Rakob, F. (1998): "Cartago. La topografía de la ciudad púnica. Nuevas investigaciones". Cuadernos de Arqueología Mediterránea 4: 15-46.

Ricci, M. (1973): "Per una cronología delle lucerne tardorepubblicane". Rivista di studi liguri 39: 168-234.

Robles, J.; Morena, J.A.; Moreno, A. y Quesada, F. (e.p.): La puerta oriental de Torreparedones (Baena, Córdoba) y sus paralelos en el contexto de las fortificaciones mediterráneas antiguas. Salsvm 8-9. Baena, Ayuntamiento de Baena.

Ruiz de Arbulo, J. (2007): "Las murallas de Tarraco: de la fortaleza romano-republicana a la ciudad tardoantigua”, en A. Rodríguez Colmenero e I. Rodà (coords.), Murallas de ciudades romanas en el occidente del imperio. Lucus Augusti como paradigma: 567-594. Lugo (2005), Lugo, Diputación Provincial de Lugo.

Sáez Abad, R. (2003): “La poliorcética. El éxito asegurado en las operaciones de asedio". Espacio, Tiempo y Forma, Serie II, Historia Antigua 16: 19-39.

Sáez Abad, R. (2004): La poliorcética en el mundo antiguo. Tesis Doctoral, Universidad Complutense de Madrid. Disponible en: https://eprints.ucm.es/5454/ (17 de mayo de 2020).

Sáez Abad, R. (2005): Artillería y poliorcética en el mundo grecorromano. Anejos de Gladius 8. Madrid, Consejo Superior de Investigaciones Científicas.

Schattner, T. G. (2003): Munigua: cuarenta años de investigaciones. Sevilla, Instituto Arqueológico Alemán.

Schattner, T.G. (2005): "La puerta de Sevilla en Carmona y otras puertas romanas en la Península Ibérica”. Romula 4: 67-98. 
Sconfienza, R. (2005): Fortificazioni tardo clasisiche e ellenistiche in Magna Grecia. I casi esemplari nell' Italia del Sud. Oxford, BAR Publishing.

Sillières, P. (1997): Baelo Claudia: una ciudad romana de la Bética. Madrid, Casa de Velázquez.

Stylow, A. (2005): "Fuentes epigráficas para la Historia de la Hispania Ulterior en época republicana” en J.F. Rodríguez Neila, E. Melchor Gil y J. Mellado Rodríguez (coords.), Julio César y Corduba: Tiempo y Espacio en la campaña de Munda (49-45 a.C.). Actas del simposio: $247-$ 262. Córdoba (2003), Córdoba, Universidad de Córdoba.

Tortajada, G. (2011): "El montaje de los batientes de las puertas", en H. Bonet y Vives-Ferrándiz (eds.), La Bastida de Les Alcusses. 1928-2010: 80-81. Valencia, Museo de Prehistoria y Arqueología.

Tristell, J.F. y López, I. (2014): "La necrópolis oriental”, en C. Márquez, J. A. Morena, A. Córdobay A. Ventura (eds.), Torreparedones -Baena, CórdobaInvestigaciones Arqueológicas (2006-2012): 110115. Córdoba, Ayuntamiento de Baena

Ulbert, G. (1983): Cáceres el Viejo. Ein spätrepublikanisches Legionslager in Spanisch-Extremadura. Madrider Beiträge. Berlín, Philipp von Zabern.
Varela, L. (2014): "La Alta Edad Media", en C. Márquez, J.A. Morena, A. Córdoba, y A. Ventura (eds.), Torreparedones-Baena, Córdoba- Investigaciones Arqueológicas (2006-2012): 124-129. Córdoba, Ayuntamiento de Baena.

Ventura, A. (2012): "Un nuevo descubrimiento epigráfico en Torreparedones". Ituci 2: 38-42.

Ventura, A. (2014): "La ocupación del territorio y la ciudad en época romana", en C. Márquez, J.A. Morena, A. Córdoba, y A. Ventura (eds.), Torreparedones -Baena, Córdoba- Investigaciones Arqueológicas (20062012): 29-37. Córdoba, Ayuntamiento de Baena.

Vicente Redón, J.; Punter, M.P. y Ezquerra, B. (1997): "La catapulta tardorrepublicana y otro equipamiento militar de "La Caridad" (Caminreal, Teruel)", en M. Feugére (ed.), L'Équipment militaire et l'armement de la République: 167-199. Oxford, Oxbow Books.

Villaronga, L. (1994): Corpus Nummum Hispaniae ante Augusti Aetatem. Madrid, José A. Herrero.

Villaronga, L. y Benages, J. (2011): Ancient coinage of the Iberian peninsla. Greek, Punic, Iberian, Roman. Les Monedes de l'Edat Antiga a la Península Ibérica. Barcelona, Institut d' Estudis Catalans.

Winter, E.F. (1971): Greek Fortifications. Oxford, Oxford University Press. 
